\title{
Synthesis of hyperbranched polymers with controlled degree of branching
}

\author{
Tomoya Higashihara ${ }^{1,2}$, Yukari Segawa ${ }^{1}$, Warapon Sinananwanich ${ }^{1}$ and Mitsuru Ueda ${ }^{1}$
}

Hyperbranched polymers (HBPs) have attracted considerable attention during the past decade because of their intrinsic globular structures and unique properties, such as low viscosity, high solubility and a high degree of functionality, compared with linear analogs. As HBPs are generally prepared by one-pot polycondensation of an $A B_{x}$ monomer, where $A$ and $B$ represent two different functional groups, they are regarded as less-expensive alternatives to dendrimers. However, HBPs have randomly branched structures and their degree of branching (DB) is determined by statistics and only reaches $\sim 50 \%$. Recently, several research groups have successfully synthesized a $100 \%$ DB without any defect mainly by condensation or addition reactions. These methods are based on a new concept in which the ratio of the rate constants, the first reaction rate constant $\left(k_{1}\right) /$ the second reaction rate constant $\left(k_{2}\right)$ of an $A B_{2}$ monomer, can be controlled. Recent development in the synthesis of a linear polymer, that is, a $0 \% \mathrm{DB} \mathrm{HBP}$, from an $\mathrm{AB}_{2}$ monomer could make it possible to further precisely control the $\mathrm{DB}$ from 0 to $100 \%$ by using the same $A B_{2}$ monomer. In this review article, the backgrounds and methodologies for controlling the $D B$ are described, especially focusing on recent advances in the synthesis of HBPs with a DB of $100,0 \%$ and any percentage between 0 and $100 \%$.

Polymer Journal (2012) 44, 14-29; doi:10.1038/pj.2011.99; published online 19 October 2011

Keywords: controlled synthesis; degree of branching; hyperbranched polymer; polycondensation; super acid

\section{INTRODUCTION}

Dendritic macromolecules have attracted considerable attention during the past decade because of their unique properties, such as low viscosity, high solubility and a high degree of functionality, compared with linear analogs. These properties are derived from the specific globular and spherical shape of the macromolecules. Dendritic macromolecules are classified into dendrons, dendrimers and hyperbranched polymers (HBPs), which are composed of successive branching units (Figure 1).

In 1985, Tomalia et al. ${ }^{1}$ and Newkome et al. ${ }^{2}$ first reported the synthesis and characterization of dendrimers, having a well-controlled size, shape and monodisperse structure, after which a significant number of research studies, ranging from poly(amidoamine), ${ }^{3,4}$ poly (propylene imine), ${ }^{5,6}$ aromatic polyethers ${ }^{7-9}$ and polyesters, ${ }^{10,11}$ aliphatic polyethers, ${ }^{12}$ polyesters, ${ }^{13}$ polyalkane, ${ }^{14,15}$ polyphenylene ${ }^{16}$ and polysilane ${ }^{17}$ dendrimers, has followed. The initial studies on dendritic polymers focused on the preparation of perfectly monodisperse dendrimers. However, the synthetic routes often involve multistep reactions with tedious isolation and purification procedures. ${ }^{18-23}$ Therefore, it was too complicated and costly to produce such dendrimers as engineering materials.

On the other hand, synthesis of HBPs, ${ }^{24-29}$ having irregularly branched and polydisperse structures, is simpler than that of dendri- mers as it does not require tedious protection/deprotection steps. The most common synthetic route involves a one-pot procedure in which $\mathrm{AB}_{\mathrm{x}}$ monomers are condensed. Such inexpensive routes would provide an advantage for mass production of HBPs.

However, HBPs have randomly branched structures, and their degrees of branching (DBs) are determined by statistics and only reach $\sim 50 \%$, as will be discussed later in detail. Recently, several research groups have successfully synthesized HBPs with a $100 \%$ DB without any defect by specially designing monomers and controlling polymerization conditions. Recent developments also include the synthesis of HBPs with a controlled DB, that is, $100,0 \%$ and any percentage between 0 and $100 \%$. In this review article, we focus on the recent progresses in the synthesis of HBPs with a controlled DB.

\section{GENERAL SYNTHETIC APPROACH}

Step-growth polymerization

The propagation reactions used for self-polycondensation of AB-type monomers are potentially useful for the synthesis of HBPs from $\mathrm{AB}_{\mathrm{x}}$-type monomers. HBPs can be synthesized by one-step selfpolycondensation reactions of $\mathrm{AB}_{\mathrm{x}}$-type monomers, as shown in Scheme 1.

$\mathrm{AB}_{2}$-type monomers are often used as starting materials because of the easy preparation of monomers while the use of $\mathrm{AB}_{3}, \mathrm{AB}_{4}$ and

${ }^{1}$ Department of Organic and Polymeric Materials, Graduate School of Science and Engineering, Tokyo Institute of Technology, Meguro-ku, Tokyo, Japan and ${ }^{2}$ Precursory Research for Embryonic Science and Technology (PRESTO), Japan Science and Technology Agency (JST), Kawaguchi, Saitama, Japan

Correspondence: Professor M Ueda, Department of Organic and Polymeric Materials, Tokyo Institute of Technology, Graduate School of Science and Engineering, 2-12-1-H-120, O-okayama, Meguro-Ku, Tokyo 152-8552, Japan.

E-mail: thigashihara@m.titech.ac.jp

Received 21 March 2011; revised 7 September 2011; accepted 9 September 2011; published online 19 October 2011 


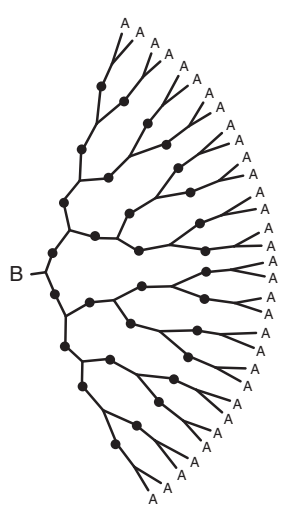

Dendron

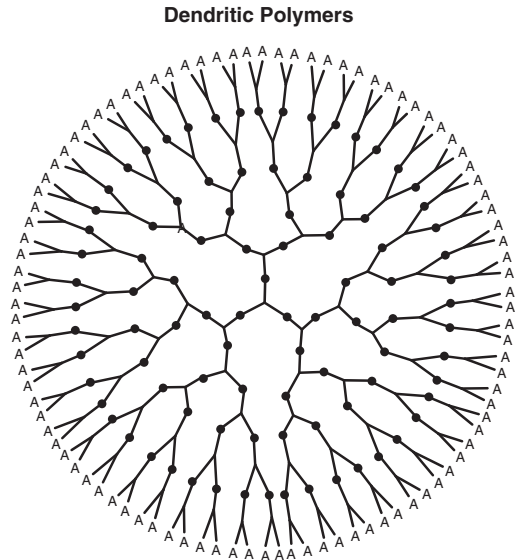

Dendrimer

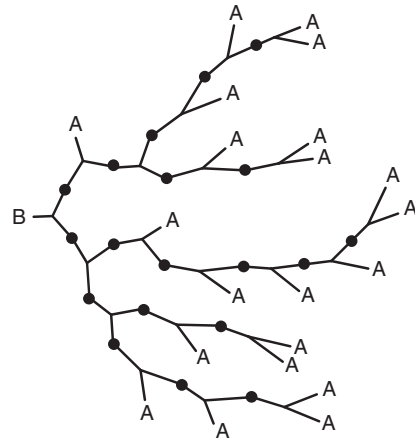

Hyperbranched Polymer

Figure 1 Structures of dendritic polymers.

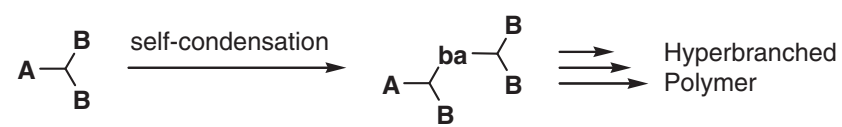

Scheme 1 Self-polycondensation of $A B_{2}$ monomer.

$\mathrm{AB}_{6}$ monomers have also been reported for the synthesis of hyperbranched polyesters, ${ }^{30}$ and polysiloxanes. ${ }^{31}$ For example, 5-acetoxyisophthalic acid was used an $\mathrm{AB}_{2}$ monomer in melt polymerization at $250{ }^{\circ} \mathrm{C}$ to prepare hyperbranched aromatic polyesters, which were insoluble in organic solvents because of the intermolecular dehydration between the carboxylic acid groups that occurred during melt polymerization. Hydrolysis of the crude product produced a soluble hyperbranched polyester having carboxylic acid groups as an end $\mathrm{B}$ function, as shown in Scheme 2. ${ }^{32}$

Aromatic-aliphatic hyperbranched polyethers, the main chains of which were composed of benzyl ether linkages, were prepared as described previously (Scheme 3). ${ }^{33}$ Polymerization was carried out in the presence of $\mathrm{K}_{2} \mathrm{CO}_{3}$ and crown ether (18-crown-6) in acetone.

\section{Self-condensing vinyl polymerization}

The term 'self-condensing vinyl polymerization (SCVP)' was defined by Fréchet et al. ${ }^{34}$ The applicable monomer denoted by $\mathrm{AB}^{\star}$ contains an initiating moiety in addition to a polymerizable double bond. After the initiating moiety is activated, it is reacted with a double bond to form a covalent bond and a new active site on the $\alpha$-carbon atom of the double bond (Scheme 4).

The number of activation sites proportionally increases with the propagation reaction in SCVP, whereas two functional groups are always consumed during polymerization of $\mathrm{AB}_{\mathrm{x}}$ monomers. If the new activation sites generated during polymerization have a different reactivity from the activation site generated from the initiating moiety of the original monomer, the structure of the resulting polymer is dramatically affected. The activated species are known as a carbocation, carbanion or radical.

The SCVP of 3-(1-chloroethyl)styrene in the presence of $\mathrm{SnCl}_{4}$ and tetrabutylammonium bromide based on cationic and radical polymerizations has been reported to produce a hyperbranched polystyrene (Scheme 5).

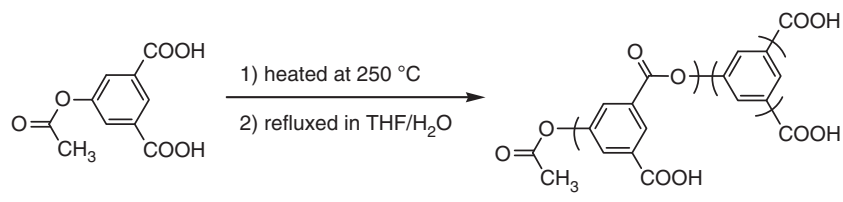

Scheme 2 Synthesis of hyperbranched aromatic polyester using 5acetoxyisophthalic acid. ${ }^{32}$

\section{Ring-opening polymerization}

The third strategy to produce HBPs is called multibranching ring-opening polymerization. Although the monomer itself does not contain branching points, they are generated through the propagation reaction, similar to SCVP. Therefore, the monomer can be recognized as a latent $\mathrm{AB}_{\mathrm{x}}$ monomer. Polymerization is promoted by the addition of a proper initiator to the monomer. As an example, glycidol contains one epoxide and one hydroxy group, representing a latent $A_{2}$ monomer for multibranching ring-opening polymerization. Hyperbranched aliphatic polyethers were successfully prepared by the anionic ring-opening polymerization of glycidol (Scheme 6). ${ }^{35}$

\section{GENERAL PROPERTIES}

Solution properties

The high solubility of HBPs induced by a branched backbone is one of the important properties that differ from those of the linear analogs. Kim and Webster ${ }^{36}$ reported that hyperbranched polyphenylenes had very good solubilities in various solvents as compared with linear polyphenylenes. Not only the solubility but also the solution behavior of HBPs differs from linear polymers. It is well known that the solution viscosity of dendritic macromolecules is lower than that of conventional linear polymers. ${ }^{32,37,38}$ Such a low viscosity indicates that dendritic macromolecules are less entangled because of their spherical shape. The relationship between intrinsic viscosity and molecular weight (MW) is shown in Figure 2.

Dendrimers display a bell-shaped relationship resulting from their regular globular structures. On the other hand, the intrinsic viscosity of HBPs increases with their increasing MW, although the slope of the plots is lower than that of linear polymers. In general, the $\alpha$-values in the Mark-Houwink-Sakurada equation range from 0.5 to 1.0 for randomly coiled linear polymers. On the other hand, many kinds of HBPs possess $\alpha$-values $<0.5$, suggesting a spherical shape of the 
molecules in a solution. Moreover, in size exclusion chromatography (SEC) measurements, the retention volume for HBPs tends to be greater than that of linear polymers having the same MWs. This also suggests a more compact formation of HBPs in a solution compared with linear polymers.

\section{Thermal properties}

Hyperbranched polymers are almost exclusively amorphous materials, although some exceptional examples have been reported in which the polymers have been modified to induce liquid crystallinity 39,40 or crystallinity. ${ }^{41}$ The lower glass transition temperature of HBPs than that of the linear counterparts is one of the most important features. The glass transition behavior is related to the relatively large segmental motions within the polymer chains, and the role of the end groups can be discarded above a certain $\mathrm{MW}$ of the linear polymer. However, for HBPs, the segmental motions are strongly affected by the branching points and the presence of numerous end groups. Therefore, the glass transition for HBPs is strongly affected by the translational movement of the entire molecule instead of a segmental movement. ${ }^{36,42}$ The chemical natures also affect the $T_{\mathrm{g}}$ values; for example, an aliphatic polyester generally has a much lower $T_{\mathrm{g}}$ value than the aromatic polyester. ${ }^{43}$

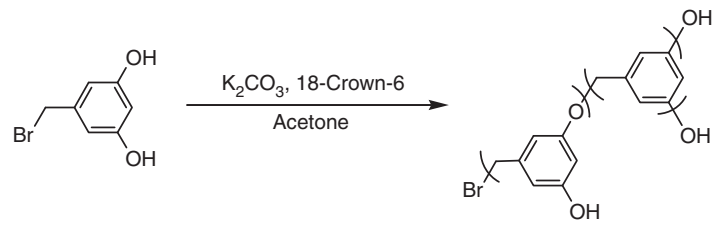

Scheme 3 Synthesis of hyperbranched polyether. ${ }^{33}$

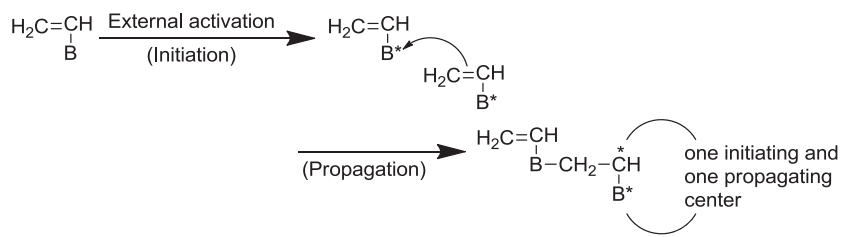

Scheme 4 Self-condensing vinyl polymerization.

\section{Mechanical and rheological properties}

The rheological properties of HBPs are characterized by a Newtonian behavior in the melt state; that is, no shear thinning or thickening is observed, ${ }^{44,45}$ indicating the lack of entanglements for these polymers. The non-entangled state imposes rather poor mechanical properties, sometimes resulting in brittle polymers. These features of HBPs have limited their use in thermoplastics in which mechanical strength is of importance.

\section{DEGREE OF BRANCHING}

In a perfectly branched dendrimer, only two types of repeating units can be distinguished: one is a dendritic unit and the other is a terminal unit. In contrast, HBPs possess three types of repeating units as illustrated in Figure 3.

The constituents are dendritic units, fully incorporated with an $\mathrm{AB}_{\mathrm{x}}$ monomer, terminal units having two unreacted $\mathrm{B}$ groups, and linear units retaining one unreacted B group. The linear segments are generally described as defects. Fréchet et al. ${ }^{46}$ defined the term 'degree of branching (DB)' as;

$$
\mathrm{DB}=(D+T) /(D+L+T)
$$

where $D, T$ and $L$ are the number of dendritic, terminal and linear units, respectively. $\mathrm{DB}$ is one of the important characteristics that indicate the branching structure of HBPs. Frey and colleagues ${ }^{47}$ reported a modified definition of $\mathrm{DB}$ based on the growth directions as;

$$
\mathrm{DB}=2 D /(2 D+L)=(D+T-N) /(D+T+L-N)
$$

where $N$ is the number of molecules. The two equations give almost the same DBs for HBPs with high MWs as $N$ in Frey's equation can be negligible in such cases. In general, it is pointed out that DB is determined by statistics and only reaches $50 \%$ for the polymers derived from the $\mathrm{AB}_{2}$ monomer, assuming the equal reactivity of the $\mathrm{B}$ functional group towards the A functional group. It should also be noted that HBPs possess many isomers even if DB is equal to $100 \%$. Hobson and Feast ${ }^{48}$ reported that there are many architectures existing for HBPs from $\mathrm{AB}_{2}$ monomers, such as a quasi-linear polymer, dendrimer wedge and perfect HBPs (Figure 4).

To date, two different techniques have been used to determine the DB. The first technique was presented by Fréchet et al. and involves the synthesis of low MW model compounds, resembling the repeating units to be found in the hyperbranched skeleton. The model compounds need to be characterized by ${ }^{13} \mathrm{C}$-nuclear magnetic resonance (NMR). On the basis of the ${ }^{13} \mathrm{C}$-NMR spectra, different peaks from

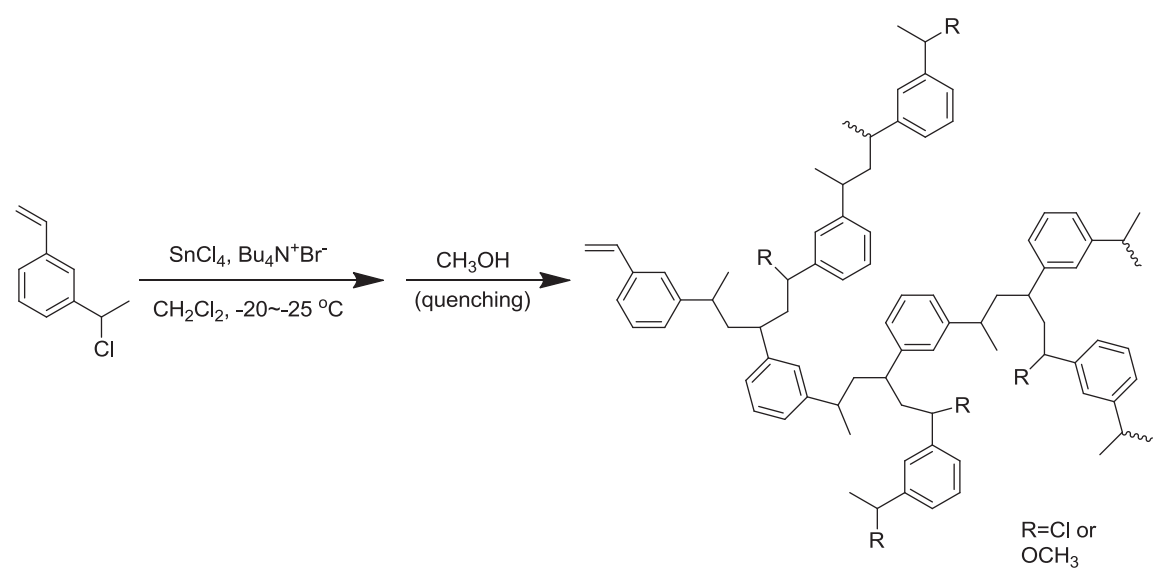

Scheme 5 Synthesis of hyperbranched polystyrene. ${ }^{34}$ 


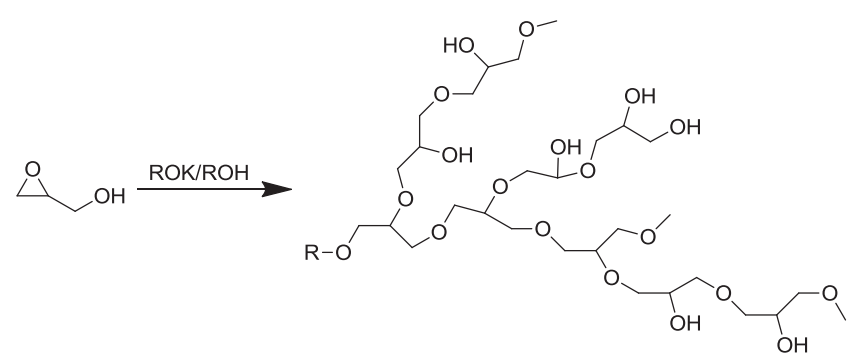

Scheme 6 Multibranching ring-opening polymerization of glycidol. ${ }^{35}$

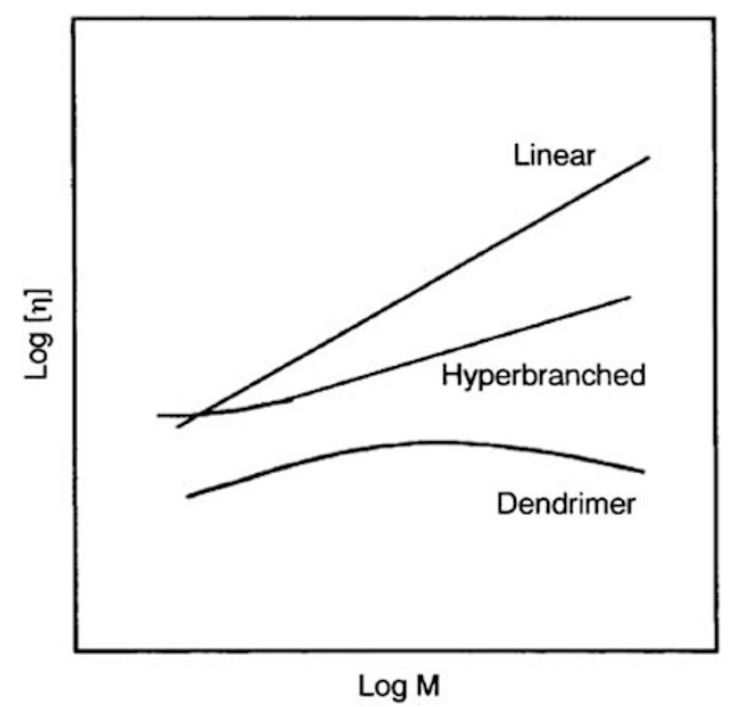

Figure 2 Schematic plots for the relationship between $\log M$ and $\log [\eta]$ for macromolecules.

the different branching units of the HBP can be assigned. The DB is calculated from integrals of the corresponding peaks. ${ }^{46}$

The second method, based on degradation of the hyperbranched backbone, was developed by Kambouris and Hawker. The chain ends are chemically modified and the hyperbranched skeleton is fully degraded by hydrolysis. The degradation products are identified using capillary chromatography. Two requirements have to be fulfilled to successfully use this technique. First, the chain ends must remain intact during the degradation reactions, and the second, conversion into elementary subunits must be completed. ${ }^{49}$

\section{CONVENTIONAL METHODS FOR INCREASING DB}

As already mentioned in the preceding section, the DB of HBPs from one-pot polymerizations of $\mathrm{AB}_{2}$ monomers statistically reaches $\sim 50 \%{ }^{47}$ To approach $100 \% \mathrm{DB}$, several chemists have attempted to increase the DB of HBPs. In 1996, Hawker and $\mathrm{Chu}^{30}$ reported the polymerization of $\mathrm{AB}_{2}, \mathrm{AB}_{3}$ and $\mathrm{AB}_{4}$ monomers composed of the same subunit to form hyperbranched poly(ether ketone)s. The DB of a polymer obtained from an $\mathrm{AB}_{4}$ monomer was $71 \%$, whereas polymerization of an $\mathrm{AB}_{2}$ monomer yielded a $\mathrm{DB}$ of $49 \%$. Kakimoto and colleagues $^{50}$ reported the synthesis of hyperbranched aromatic polyamides from $A_{2}$ and $A_{4}$ monomers. The $\mathrm{DB}$ of a $\mathrm{HBP}$ was determined to be $72 \%$ by using an $\mathrm{AB}_{4}$ monomer as the starting material, although polymerization of an $\mathrm{AB}_{2}$ monomer, that is, 3,5diaminobenzoic acid, results in a relatively low DB of $32 \%$ because of

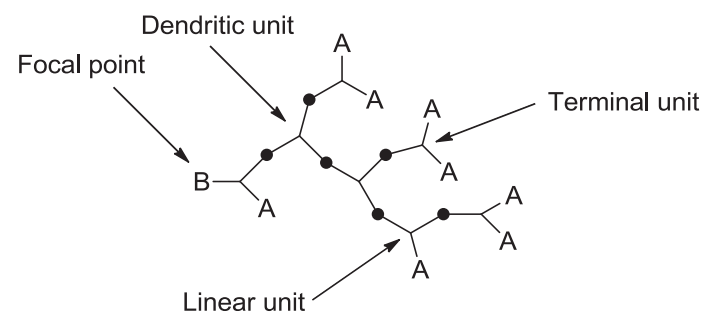

Figure 3 Different segment types present in HBPs. HBP, hyperbranched polymer.

its steric hindrance. Hyperbranched aliphatic polyesters with a DB $>80 \%$ have also been prepared by melt polymerization of an $\mathrm{AB}_{2}$ monomer in the presence of a $\mathrm{B}_{3}$ comonomer, significantly reducing the linear units within the branched architecture (Scheme 7). ${ }^{51,52}$ It should be noted that the increase in the DB by these strategies is not directly related to the formation of globular molecules, but is mainly due to the decrease in the linear units.

When reactivity of the $\mathrm{B}$ function is enhanced by formation of a linear unit $\left(k_{\mathrm{L}}>k_{\mathrm{T}}\right.$, Scheme 8$)$, the amount of dendritic units would be increased during polymerization of $\mathrm{AB}_{\mathrm{x}}$ monomers. Frey and coworkers proposed a theoretical rule in the relationship between the ratio of rate constant $\left(k_{\mathrm{L}} / k_{\mathrm{T}}\right)$ and $\mathrm{DB}$ for general $\mathrm{AB}_{\mathrm{x}}$ monomers. For instance, $\mathrm{DB}$ values of $80 \%$ can be expected for polymerization of $\mathrm{AB}_{2}$ monomers when $k_{\mathrm{L}}$ is five times greater than $k_{\mathrm{T}}{ }^{53}$

Indeed, hyperbranched aliphatic polyamines with high DBs $(60-80 \%)$ have been synthesized by multibranching ring-opening polymerization of a cyclic carbamate initiated by primary amines. ${ }^{54,55}$ It was assumed that $k_{\mathrm{L}}$ became higher than $k_{\mathrm{T}}$ during polymerization because the secondary amines in the linear units were more reactive as nucleophiles than the primary amines in the terminal units.

Frey and colleagues tried to synthesize an HBP with a DB of $100 \%$ (Scheme 9). They combined the reaction sequence of (1) a hydrosilylation reaction of triallylsilane to prepare a conventional hyperbranched poly(triallysilane) with an uncontrolled DB and (2) the chain-end modification with trichlorosilane through a hydrosilylation reaction, followed by the subsequent nucleophilic displacement of the chloride into allyl groups using allylmagnesium bromide. The reaction sequence (1) and (2) resulted in a hyperbranched poly(triallysilane) with $\mathrm{DB}=100 \%{ }^{56}$

\section{HBPS WITH $100 \%$ DB}

\section{Cycloaddition of azine and diisocyanate}

There have been several studies that reported strategies to increase the $\mathrm{DB}$, but they are limited to the use of $\mathrm{AB}_{\mathrm{x}}$ monomers with $\mathrm{B}$ groups of equal reactivity. Komber and colleagues first presented a new strategy which avoids this limitation. It is based on the molecular design of an $\mathrm{AB}_{2}$ monomer with two initially identical $\mathrm{B}$ groups, but which dependently react with an A group. In their system, when one $B$ group reacts with an A group, an unstable intermediate is reversibly formed. The equilibrium of the reaction lies back to the unreacted $\mathrm{B}$ group. Once the generated intermediate reacts with another A group, a stable reactant is obtained. The second step is irreversible under the used reaction conditions. In other words, only terminal or dendritic units are selectively formed, because the linear units exist as unstable intermediates. As a result, the $\mathrm{HBP}$, synthesized from the specially designed $\mathrm{AB}_{2}$ monomer, should have a $100 \%$ DB. ${ }^{57}$

They applied the 'criss-cross' cycloaddition of azine and diisocyanate to the synthesis of a HBP with a $100 \%$ DB. The mechanism involves the reversible formation of an unstable azomethinimine, 
a

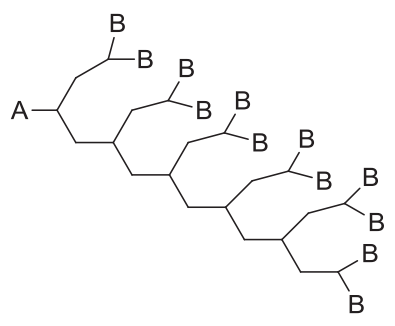

b

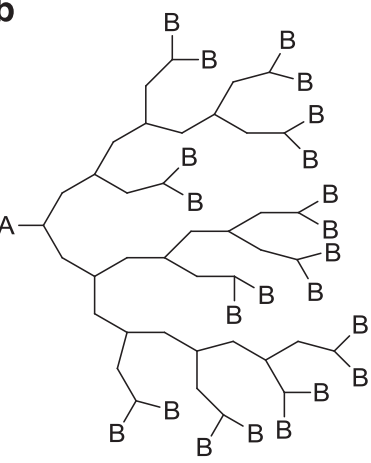

C

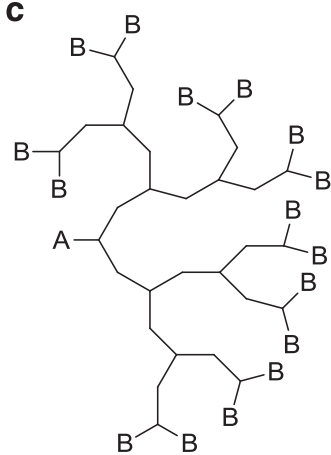

Figure 4 Possible structure of $A B_{2} \mathrm{HBPs}$ with $\mathrm{DB}=1$. (a) Quasi-linear polymer, (b) dendrimer wedge and (c) perfect $\mathrm{HBP}$. DB, degree of branching; HBP, hyperbranched polymer.

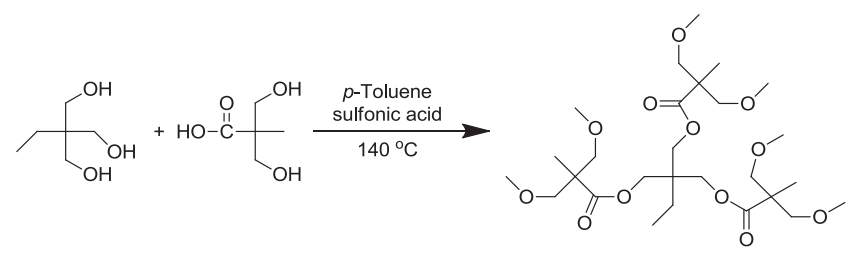

Scheme 7 Polymerization of an $A B_{2}$ monomer in the presence of a $B_{3}$ comonomer. ${ }^{51,52}$

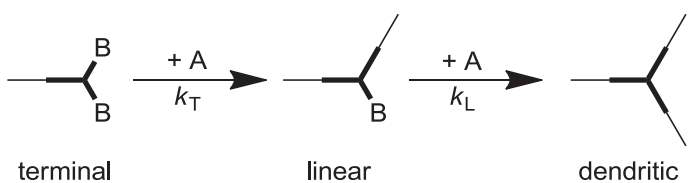

Scheme 8 The rate constant of the first and the second reactions of $A B_{2}$ monomer. which either decomposes into isocyanate and azine or adds another isocyanate group to form a stable bicyclic structure. Polymerization of the monomer, which contains maleimide and azine, was carried out by melt condensation at $185^{\circ} \mathrm{C}$ for $15 \mathrm{~min}$ to afford an HBP with $100 \%$ DB (Scheme 10).

\section{Use of isatin compounds}

Thereafter, Smet et al. ${ }^{58}$ carried out the acid-catalyzed condensation of an isatin-based $\mathrm{AB}_{2}$-type monomer with a highly reactive phenoxy group in trifluoromethanesulfonic acid (TFSA), a 'super acid', for synthesis of hyperbranched poly(arylene oxindole) with a $100 \%$ DB (Scheme 11). As it is well known that condensation of isatin and aromatic compounds under acidic conditions exclusively yields 3,3-diaryl oxindoles because of instability of the mono-condensed intermediate, the possibility of generating linear units in the HBP is totally denied, resulting in a $100 \% \mathrm{DB}$. On the basis of this success, they also orthogonally modified the HBP to convert it into unimolecular micelle-like structures with a long alkyl chain or ammonium salt formation at the periphery. The latter ammonium-modified HBP led a water-soluble macromolecule binding to an apolar probe dye. ${ }^{59}$ In addition, core shell-type star polymers composed of poly(tert-butyl methacrylate) arms and 100\% hyperbranched poly(arylene oxindole) interiors were successfully synthesized with the 'core-first' method. ${ }^{60}$

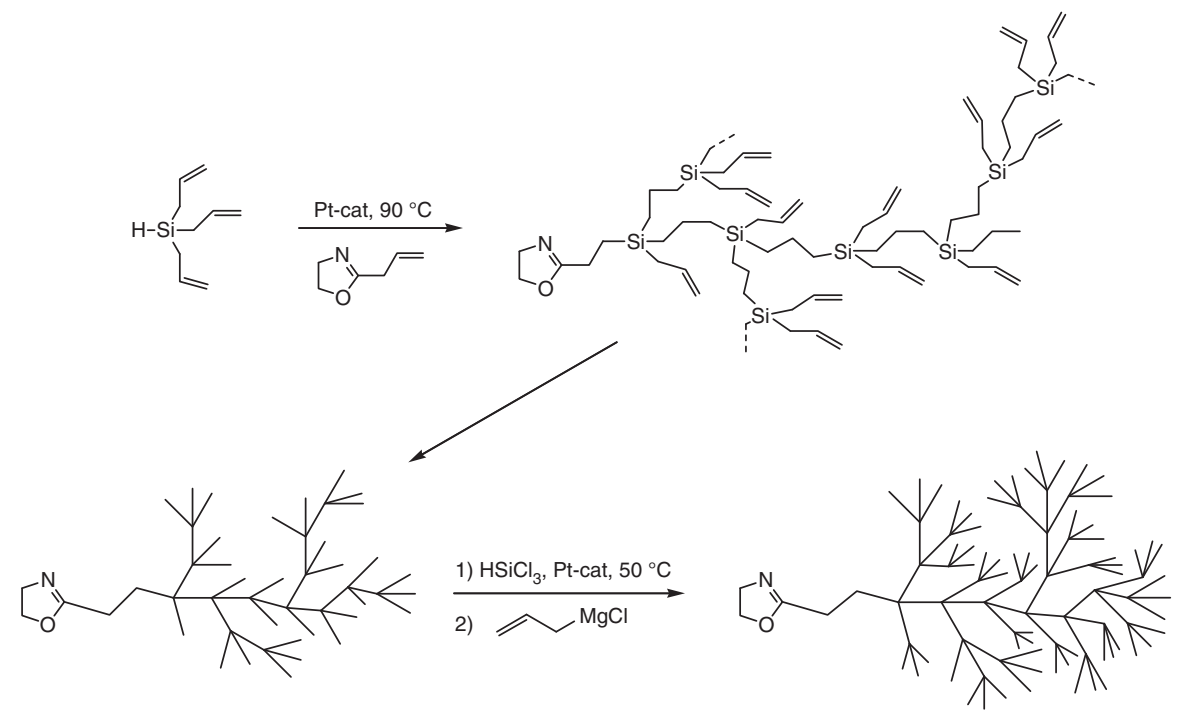

Scheme 9 Synthesis of poly(triallylsilane) with 100\% DB based on a chain-end modification approach. ${ }^{56}$ DB, degree of branching. 


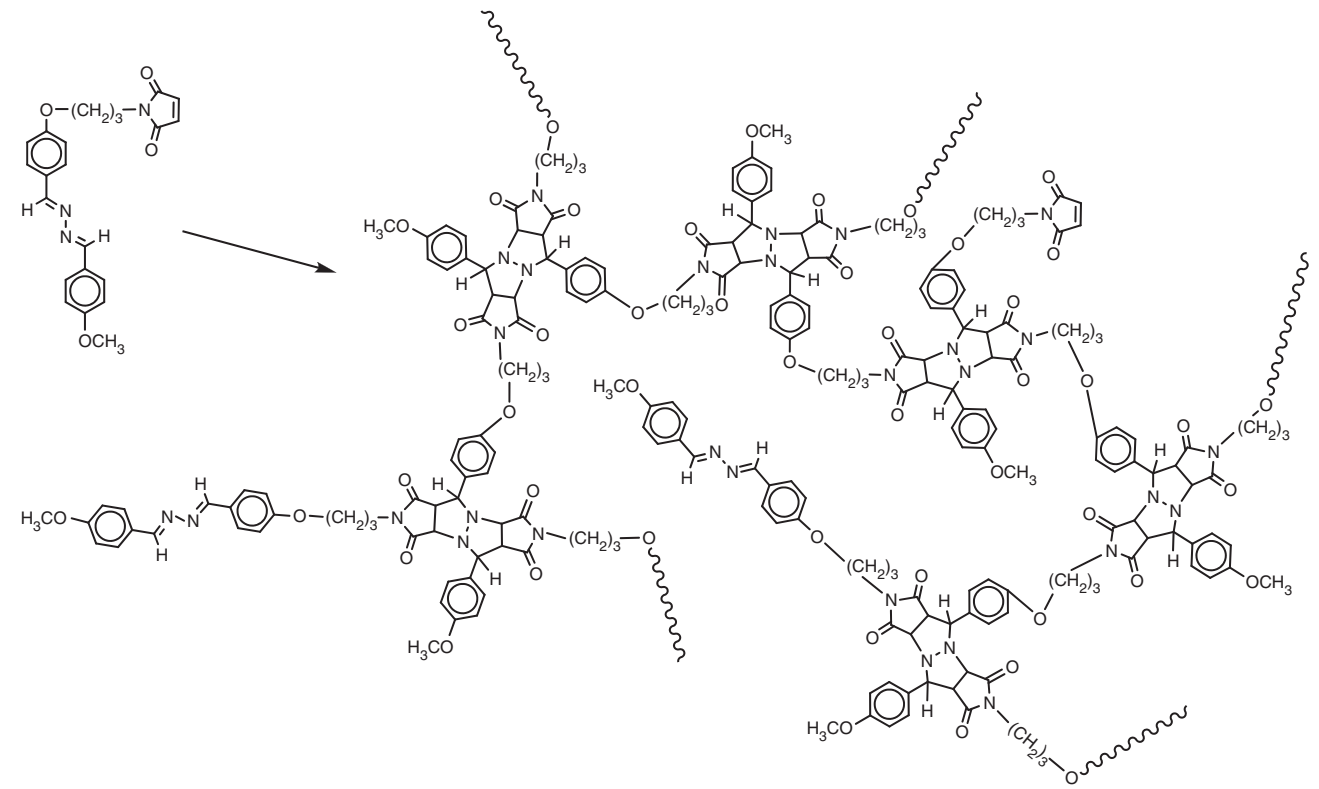

Scheme 10 Synthesis of a hyperbrnached polymer with 100\% DB by cycloaddition. ${ }^{57}$ DB, degree of branching.

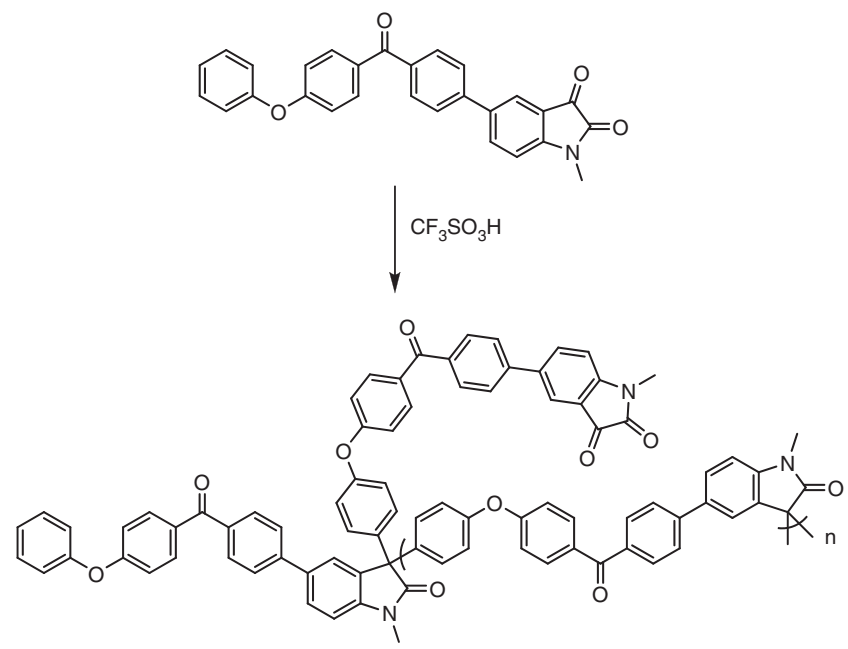

Scheme 11 Synthesis of hyperbranched poly(arylene oxindole) with $100 \%$ DB. ${ }^{58}$ DB, degree of branching.

\section{Use of acenaphthenequinone compounds}

Smet and colleagues ${ }^{61}$ also reported the synthesis of hyperbranched poly(acenaphthenone)s with $100 \% \mathrm{DB}$ by polymerizing an $\mathrm{AB}_{2}$ monomer, in which a phenoxybenzophenone and two acenaphthenequinone units are $\mathrm{A}$ and $\mathrm{B}_{2}$ functionalities (Scheme 12). This system can be used in methanesulfonic acid, which is less costly and less toxic than TFSA. It is well known that acidity of the reaction medium has a critical role in superelectrophilic chemistry. ${ }^{62-64}$ The availability of methanesulfonic acid instead of TFSA indicates that the superelectrophilic reactivity of the acenaphthenequinone-based $\mathrm{AB}_{2}$ monomer is remarkably higher than that of isatin analogs. They suggested that this is because acenaphthenequinone, compared with isatin, does not possess a nitrogen atom adjacent to the carbonyl group, from which the carbonyl might delocalize electron density and hence be deactivated.

\section{Use of fluorenone compounds}

As already mentioned, diarylation of activated carbonyl compounds such as isatins quantitatively proceeds in the presence of an acid. In contrast, ordinary ketones, such as fluorenone, show poor reactivity for the diarylation. For instance, $\mathrm{HCl}$ catalyzes the condensation of fluorenone with phenol to afford the corresponding diarylated compound in a $46 \%$ yield in 2 days. ${ }^{65}$ However, Yamada et al. ${ }^{66}$ demonstrated that diarylation of fluorenone effectively proceeds when 3-mercaptopropionic acid (MPA) is added to the reaction mixture at $65^{\circ} \mathrm{C}$.

Thus, the model reaction between 9-fluorenone (1) and anisole (2) was first investigated in the presence of MPA in trifluoroacetic acid. ${ }^{67}$ The reaction between 1 and 2 ( 0.80 equivalent) was conducted at $60{ }^{\circ} \mathrm{C}$ for $20 \mathrm{~h}$ in the presence of $3 \mathrm{~mol} \%$ MPA. Figure 5 illustrates the changes in the consumption of $\mathbf{1}$ and $\mathbf{2}$ and the yield of the diarylated product of 3 with time, as determined by ${ }^{1} \mathrm{H}-\mathrm{NMR}$. The yield of $\mathbf{3}$ increased with the decreasing concentrations of $\mathbf{1}$ and 2; these values had a complementary relationship, indicating that no side reaction occurred during condensation. Consequently, the reaction rate constant of the second step, namely $k_{2}$, is much higher than that of the first step, that is, $k_{1}$.

To investigate the reaction mechanism in more detail, the kinetics was plotted based on the following equations (Scheme 13) where I is an intermediate. Moreover,

$$
\begin{aligned}
& -\mathrm{d}[\mathbf{2}] / \mathrm{dt}=k_{1}[\mathbf{1}][\mathbf{2}]+k_{2}[\mathrm{I}][\mathbf{2}] \\
& -\mathrm{d}[\mathbf{1}] / \mathrm{dt}=k_{1}[\mathbf{1}][\mathbf{2}], \\
& \mathrm{d}[\mathbf{I}] / \mathrm{dt}=k_{1}[\mathbf{1}][\mathbf{2}]-k_{2}[\mathbf{I}][\mathbf{2}],
\end{aligned}
$$

and

$$
\mathrm{d}[\mathbf{3}] / \mathrm{dt}=k_{2}[\mathbf{I}][\mathbf{2}] ;
$$

if $k_{1} \ll k_{2}$, the amount of intermediate $\mathbf{I}$ can be ignored in the steady state. Thus,

$$
\mathrm{d}[\mathbf{I}] / \mathrm{dt}=0 .
$$




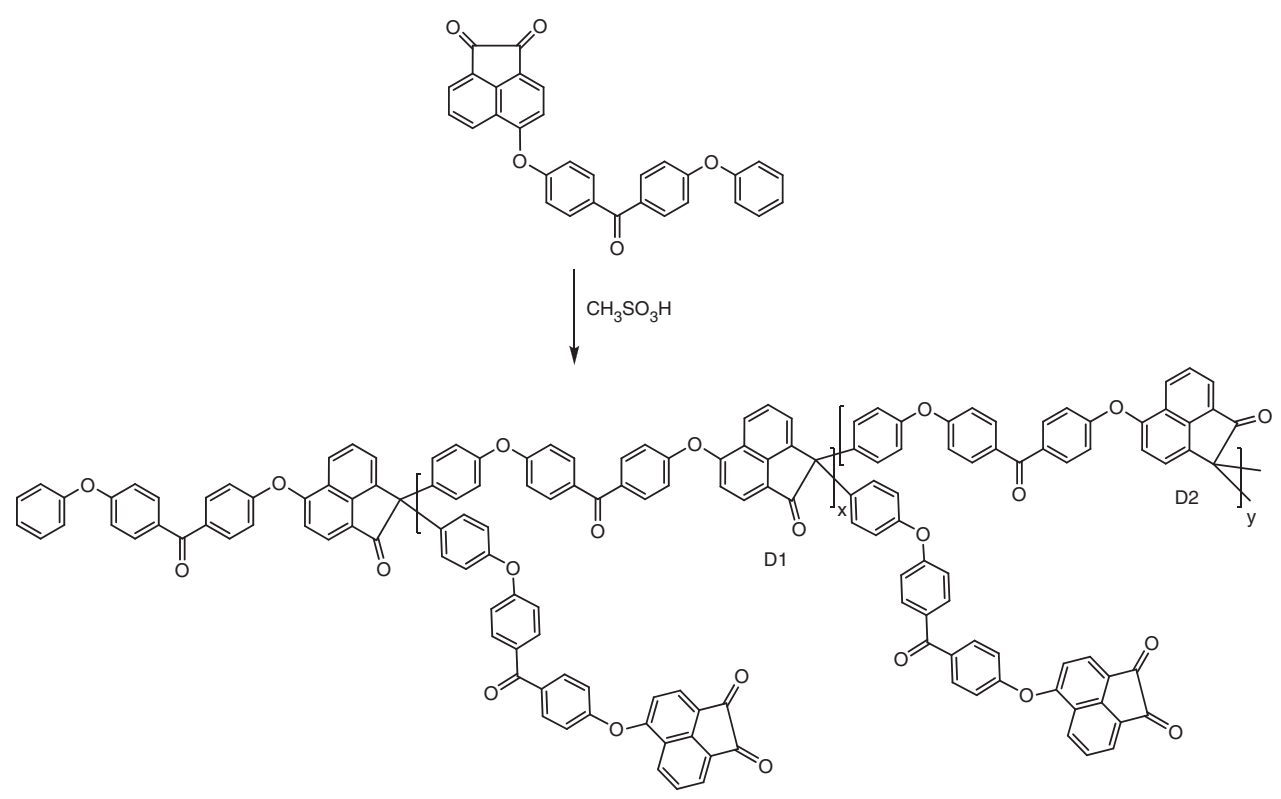

Scheme 12 Synthesis of hyperbranched poly(acenaphthenone) with $100 \% \mathrm{DB}^{61}$. DB, degree of branching.

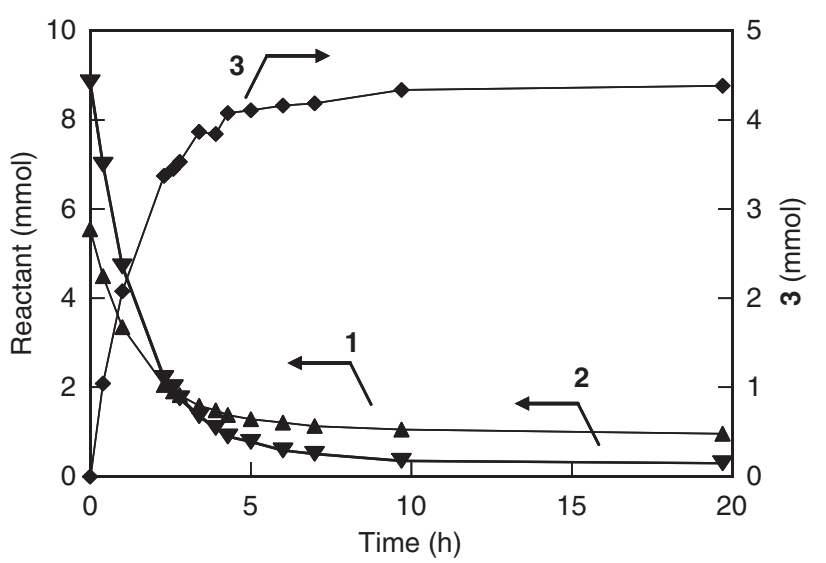

Figure 5 Relationship between the amounts of reactants, that is, $\mathbf{1}(\mathbf{\Lambda})$ and $\mathbf{2}(\mathbf{\nabla})$ and the diarylated product $\mathbf{3}(\diamond)$ with reaction time. 67

From equations (3) and (5), the concentration of I can be expressed as follows:

$$
[\mathbf{I}]=k_{1} / k_{2}[\mathbf{1}] \text {. }
$$

Equation (4) can then be expressed using equation (6) as

$$
\mathrm{d}[3] / \mathrm{dt}=k_{1}[\mathbf{1}][2] .
$$

The concentrations of $\mathbf{1}$ and $\mathbf{2}$ are given by

$$
[\mathbf{1}]=[\mathbf{1}]_{0}-[\mathbf{3}] \text { and }[\mathbf{2}]=[\mathbf{2}]_{0}-2[\mathbf{3}] \text {. }
$$

Therefore, equation (7) is written as

$$
\mathrm{d}[\mathbf{3}] / \mathrm{dt}=k_{1}\left([\mathbf{2}]_{0}-2[\mathbf{3}]\right)\left([\mathbf{1}]_{0}-[\mathbf{3}]\right) .
$$

This expression can be integrated under the condition that $[\mathbf{3}]=0$ when time $t=0$ as follows:

$$
\ln ([\mathbf{1}] /[\mathbf{2}])=\left(2[\mathbf{1}]_{0}-[\mathbf{2}]_{0}\right) k_{1} \mathrm{t}+\ln \left([\mathbf{1}]_{0} /[\mathbf{2}]_{0}\right) .
$$

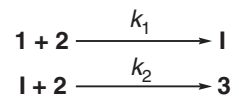

Scheme $\mathbf{1 3}$ Rate constants for the reactions between $\mathbf{1}$ and $\mathbf{2}$, and $\mathbf{I}$ and $\mathbf{2}$.

Figure 6 shows a linear relationship between $\ln ([1] /[2])$ and time; the overall reaction rate $(k)$ and the correlation coefficient were estimated to be $0.09171 \mathrm{~mol}^{-1} \mathrm{~s}^{-1}$ and 0.995 , respectively. These results indicate that the first reaction, that is, the reaction between $\mathbf{1}$ and $\mathbf{2}$, is the ratelimiting step in the condensation.

The proposed reaction mechanism is illustrated in Scheme 14. The fast protonation of $\mathbf{1}$ produces the activated carbonyl compound, which undergoes nucleophilic addition with MPA. The fast dehydration of this hemiacetal affords stable fluorenylidene alkylsulfonium, which slowly reacts with 2 . The formation of the corresponding tertiary cation followed by nucleophilic addition with 2 rapidly proceeds to yield 3 .

On the basis of these findings, a new $\mathrm{AB}_{2}$ monomer was designed and synthesized, in which $A$ and $B_{2}$ correspond to the phenoxy and 9-fluorenone groups, respectively. Self-polycondensation of the $\mathrm{AB}_{2}$ monomer was carried out in the presence of MPA in methanesulfonic acid/dichloromethane (v/v, 1:1) at $40^{\circ} \mathrm{C}$ (Scheme 15). Polymerization proceeded in the homogeneous solution, resulting in an $81 \%$ yield of the HBP. On the basis of ${ }^{13} \mathrm{C}-\mathrm{NMR}$ spectroscopy, only the carbonyl and quaternary carbons at the terminal and dendritic units, respectively, were observed, whereas the quaternary carbon of the linear units was absent. This result indicates that the DB of the HBP is $100 \%$.

Thioacetals and thioketals, which are widely used for protection of aldehydes and ketones, can be prepared using acid catalysts ${ }^{68,69}$ or other transition metal catalysts, such as titanium tetrachloride, ${ }^{70}$ magnesium or zinc triflates, ${ }^{71}$ lanthanum chloride ${ }^{72}$ and Nafion$\mathrm{H}^{73}$ These compounds are involved in the initial formation of hemithioacetals and hemithioketals, which are generally unstable for isolation and react immediately with thiol groups. Furthermore, 
thioacetals and thioketals are generally resistant to acid hydrolysis. Therefore, these thioacetal and thioketal reactions could be used for synthesis of HBPs with $100 \%$ DB. Indeed, hyperbranched poly(thioketal) with $100 \%$ DB was successfully prepared using 2-[4-(4-mercaptobutoxy)phenoxy]-9H-fluoren-9-one as an $\mathrm{AB}_{2}$ monomer in

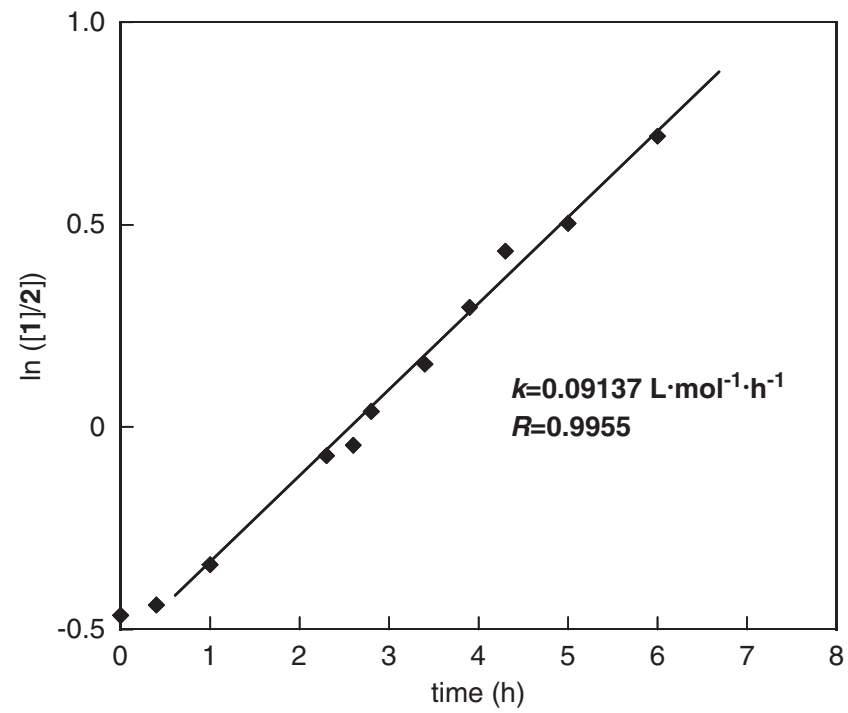

Figure 6 Second-order kinetic plot for the condensation of 9-fluorenone (1) and anisole (2). ${ }^{67}$ trifluoroacetic acid, in which $\mathrm{A}$ and $\mathrm{B}_{2}$ functionalities correspond to the thiol and 9-fluorenone groups, respectively (Scheme 16). ${ }^{74}$ The kinetics of the model reaction between 9-fluorenone and MPA was also reported in detail. ${ }^{74}$ The kinetic study clarified that the reaction obeyed second-order kinetics, in which the first reaction, which is the formation of the intermediate from 9-fluorenone and MAP, is considerably slower than the second reaction, which is the reaction of the intermediate with MPA.

\section{Use of piperidine-4-one compounds}

There are many examples in physical-organic studies that use throughspace electronic interactions to control regiospecificities and stereospecificities. ${ }^{75-77}$ Molecules, such as 4 -substituted bicycle[2.2.0] octane-1-carboxylic acid, were developed to determine the Coulombic interaction between a polar substituent and carboxylic acid. The through-space electrostatic interaction between these groups affects the $\mathrm{p} K_{\mathrm{a}}$ of the carboxylic acid group. ${ }^{78,79}$ Seto and colleagues described this physical-organic strategy to control the potency of enzyme inhibition. They found that the piperidine-4-one ring system is the most reactive toward nucleophilic attack by water or thiols. ${ }^{80}$ Klumpp et al. ${ }^{81}$ used this activation for synthesis of aryl-substituted piperidines by the Friedel-Craft-type reaction of a piperidine-4-one with benzene. The proposed reaction mechanism was that the origin of such an enhanced reactivity is located at the base site of the nitrogen atom and that the protonated nitrogen induces electrophilicity of a carbonyl group, which is readily condensed with aromatic nucleophiles. This activation may arise from inductive effects or through-space electro-

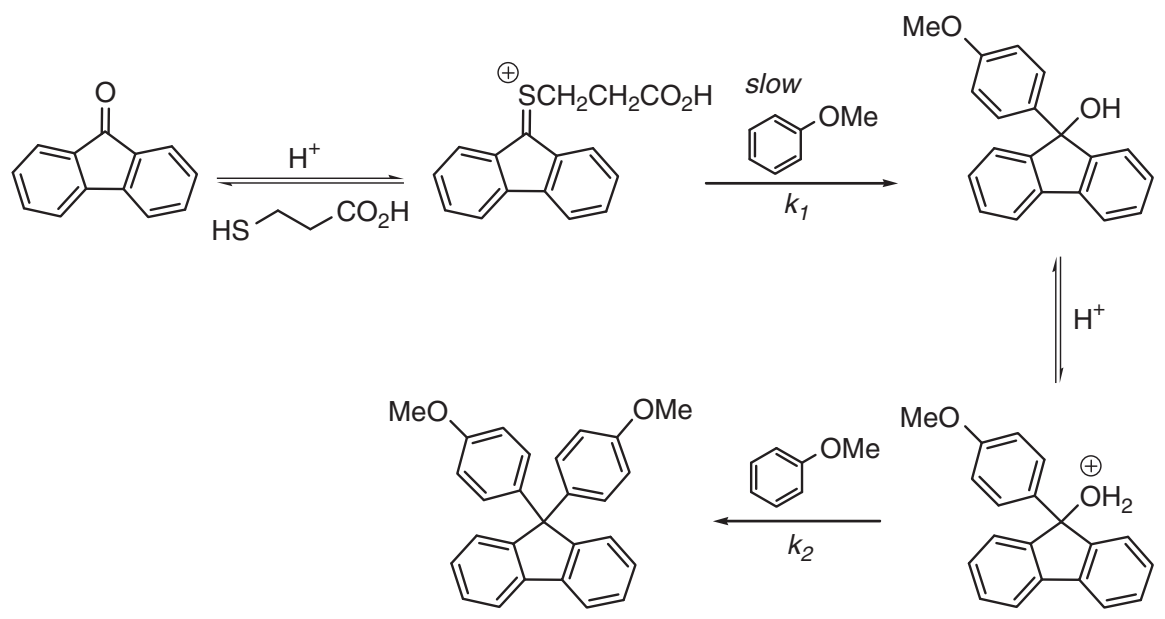

Scheme 14 Proposed mechanism of diarylation reaction of 9-fluorenone (1). ${ }^{67}$

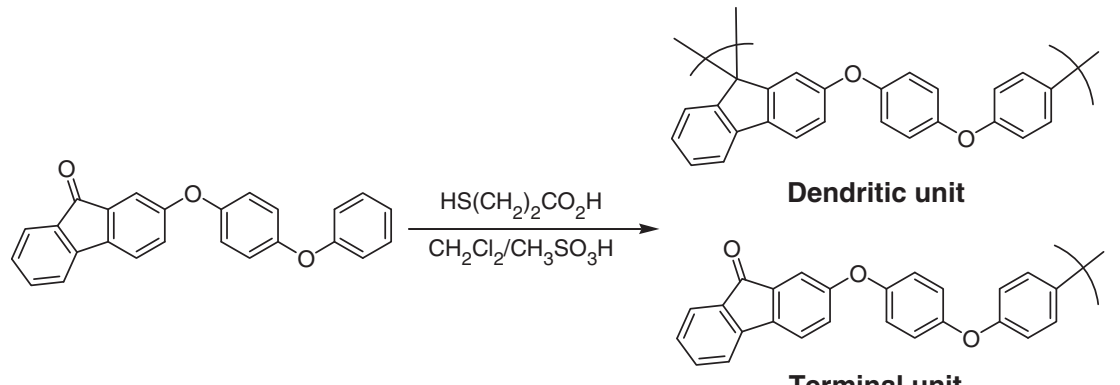

Scheme 15 Synthesis of hyperbranched poly(fluorenone) with $100 \%$ DB. ${ }^{67}$ DB, degree of branching. 


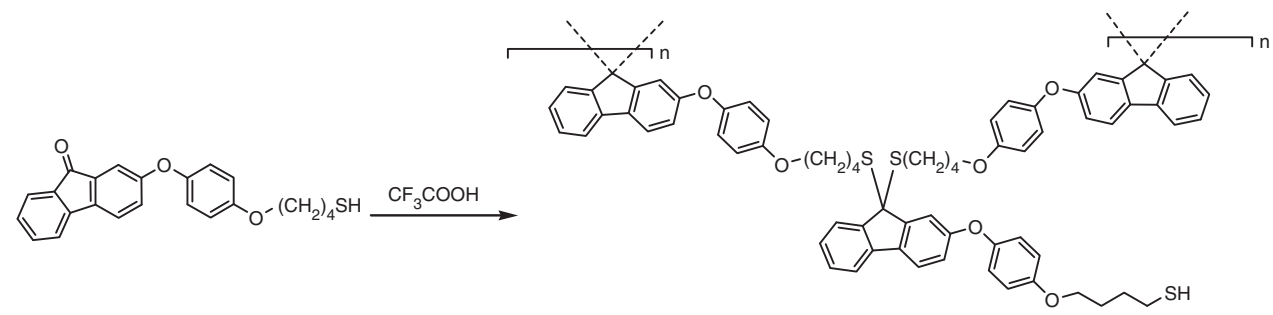

Scheme 16 Synthesis of hyperbranched poly(thioketal) with $100 \%$ DB. ${ }^{74}$ DB, degree of branching.

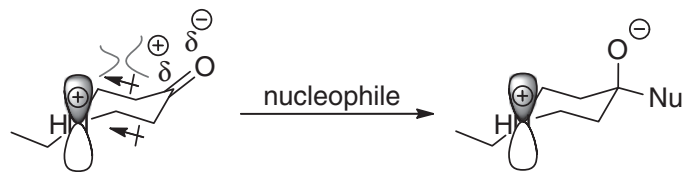

Scheme 17 Electrostatic model proposed for the substitution by an aromatic nucleophile in the presence of acid catalyst. ${ }^{82-84} \mathrm{DB}$, degree of branching.

static effects (Scheme 17). ${ }^{82-84}$ Furthermore, when an alcohol intermediate is formed in an acidic solution, it will rapidly react with another aromatic compound to yield a diarylated product. However, thermodynamically favorable disubstituted products have been found to be poorly reversible in acid hydrolysis. ${ }^{85}$ Despite the importance of these studies, through-space interactions are rarely used as a rational design element in polymer synthesis.

In practice, an HBP with a $100 \%$ DB has been successfully prepared based on through-space interactions using 1-(3-phenoxypropyl)piperidine-4-one as the $\mathrm{AB}_{2}$ monomer in the presence of methanesulfonic acid (Scheme 18). ${ }^{86}$ The model reaction followed second-order kinetics, indicating that the first reaction, that is, the formation of the intermediate from the reaction between 1-ethylpiperidine-4-one and anisole, is considerably slower than the second reaction, that is, the reaction of the generated intermediate with anisole.

\section{Base-catalyzed system using indoline-2-one compounds}

In general, high MWs of linear polymers from the step-growth polymerization are obtained with a stoichiometric amount of monomers, whereas a stoichiometric imbalance in the monomer feed ratio significantly decreases the degree of polymerization. However, there are some exceptions that high MW polymers can still be obtained under a non-stoichiometric condition in step-growth polycondensation, in which the first condensation reaction of a bifunctional monomer enhances the second one. In other words, the degree of polymerization can be increased when polymerization proceeds through a highly reactive intermediate. Indeed, Endo and colleagues ${ }^{87}$ reported that a linear poly(orthocarbonate) with a high MW was prepared by polycondensation of a 0.7 equivalent excess of 2,2dichloro-1,3-benzodioxole with bisphenol A. They found that the rate constant of the first nucleophilic displacement was 27 times slower than that of the second one. In addition, the reaction of bisphenol A with methylene bromide in the presence of sodium hydroxide produced a high MW aromatic polyformal. The proposed reaction mechanism shows that the reaction took place through a bromomethyl ether intermediate, which is much more reactive than the monomer of methylene dibromide. ${ }^{88}$ Ueda and colleagues ${ }^{89}$ also studied the kinetics of the polycondensation of 4,4-thiobisbenzenethiol and dibromomethane and found that a high MW poly(phenylene thioether) was successfully obtained under a non- stoichiometric condition. Therefore, it was envisioned that a geminal dihalide functional group can be applied to the $B_{2}$ groups in an $A_{2}$ monomer for the synthesis of HBPs with a $100 \%$ DB.

On the basis of this concept, the based-catalyzed synthesis of a novel HBP with a $100 \%$ DB was demonstrated using 3,3-dibromo-1-hexyl5-hydroxyindolin-2-one as an $\mathrm{AB}_{2}$ monomer in the presence of sodium hydride (Scheme 19). ${ }^{90}$ The monomer structure is based on an indolin-2-one core having geminal dibromide and hydroxyl functional groups, which is designed to react together forming an irreversible ketal compound. A kinetic model reaction between 3,3dibromo-1-hexylindolin-2-one and 4-methylphenol was studied in a base medium. The reaction followed second-order kinetics, indicating that the first reaction, that is, the formation of an intermediate from a reaction between 3,3-dibromo-1-hexylindolin-2-one and sodium 4methylphenolate, is considerably slower than the second reaction, that is, the reaction of the generated monobromide ether with sodium 4methylphenolate. As a result, the expected HBP with a 100\% DB could be synthesized, as confirmed by the ${ }^{13} \mathrm{C}-\mathrm{NMR}$ analysis.

\section{Catalyst transfer Suzuki-Miyaura polycondensation}

Sinclair and Sherburn ${ }^{91}$ reported that the Suzuki-Miyaura coupling of diiodoaryls and arylboronic acid in a feed ratio of 10:1 with $\mathrm{Pd}\left(\mathrm{PPh}_{3}\right)_{4}$ as the catalyst preferentially afforded the disubstituted product. Dong and $\mathrm{Hu}^{92}$ also reported that only a disubstituted product was formed by the Suzuki coupling of dibromobenzenes with one equivalent of arylboronic acid using $\mathrm{Pd}_{2}(\mathrm{dba})_{3}$ and $\mathrm{P}(t-\mathrm{Bu})_{3}$. Soon after, Scherf and colleagues $^{93}$ also found that the coupling of 2,7-dibromofluorene with one equivalent of arylboronic acid proceeded to selectively afford diaryl-substituted fluorenes. The chain-growth Suzuki-Miyaura polymerization of bromoarylboronic acid using $\mathrm{P}(t-\mathrm{Bu})_{3} \mathrm{Pd}(\mathrm{Ph}) \mathrm{Br}$ as the catalyst was demonstrated by Yokozawa and coworkers. ${ }^{94}$ Recently, Bo and coworkers ${ }^{95}$ succeeded in synthesizing HBPs with a $100 \%$ DB by the catalyst transfer Suzuki-Miyaura polycondensation. As shown in Scheme 20, they used newly designed $\mathrm{AB}_{2}$ monomers containing one aromatic boronic pinacol ester and two aromatic bromo atoms linked by an alkyl chain spacer. HBPs with a $100 \%$ DB could be prepared by the catalyst transfer Suzuki-Miyaura polycondensation of $\mathrm{AB}_{2}$ monomers in a biphasic mixture of tetrahydrofuran (THF) and aqueous $\mathrm{NaHCO}_{3}$ with $\mathrm{Pd}_{2}(\mathrm{dba})_{3}$ and $\mathrm{P}(t-\mathrm{Bu})_{3}$, as confirmed by an NMR analysis showing the absence of linear units in the products. They hypothesized the formation mechanism of HBPs with a $100 \%$ DB (also see Scheme 20) as follows: (1) oxidative addition of the Pd species to the aryl-bromo bond, (2) transmetallation and reductive elimination to form a CC bond between two aryls, (3) formation of a complex between the $\operatorname{Pd}(0)$ species and the aromatic ring, preventing diffusion of the Pd species to the reaction media, (4) oxidative addition of the $\operatorname{Pd}(0)$ species into the neighboring aryl-bromo bond by catalyst transfer through the $\pi$ system and (5) transmetallation, reductive elimination and diffusion of the $\operatorname{Pd}(0)$ species into the reaction media. 


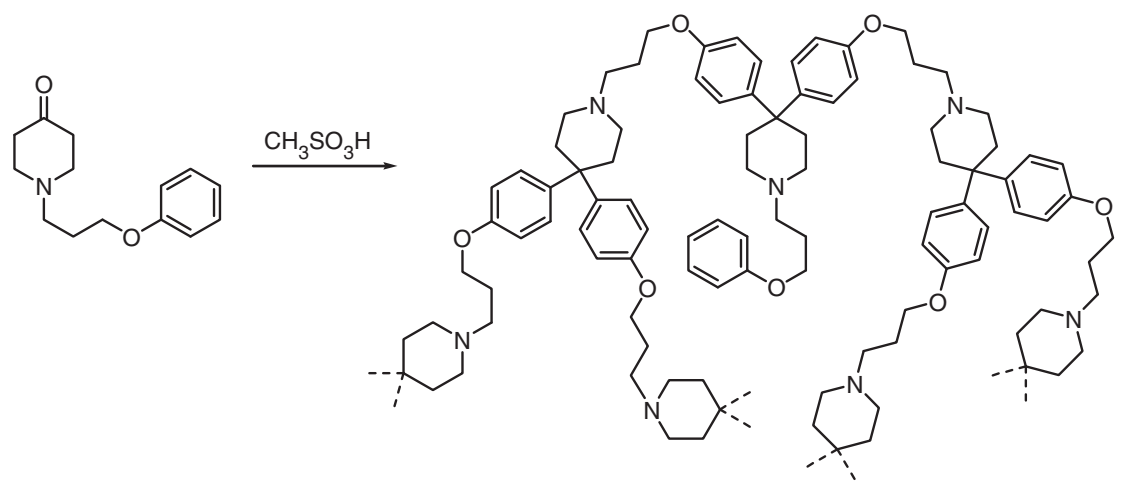

Scheme 18 Synthesis of pyperidine-based HBP with 100\% DB. ${ }^{86}$ DB, degree of branching; HBP, hyperbranched polymer.

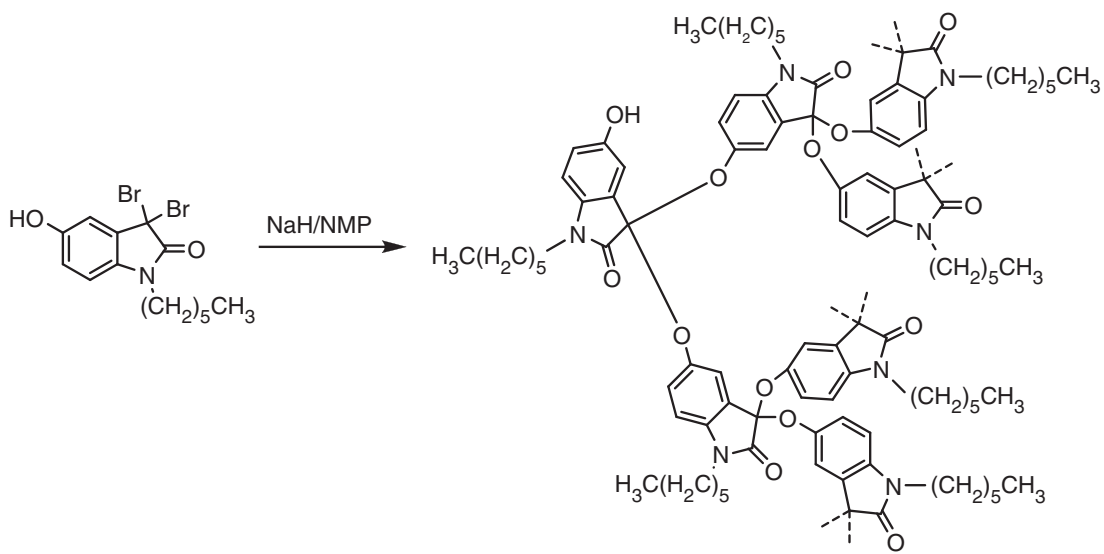

Scheme 19 Base-catalyzed synthesis of HBP with $100 \%$ DB. ${ }^{90}$ DB, degree of branching; HBP, hyperbranched polymer.

\section{LINEAR POLYMERS DERIVED FROM $\mathrm{AB}_{\mathbf{2}}$ MONOMERS}

The hydroxyalkylation reaction is one of the most versatile CCforming reactions at the carbonyl carbon of activated aldehydes or ketones with various types of aromatic compounds, thus providing a convenient method for the synthesis of sec-and tert-aromatic alcohols. However, more often, the initially formed alcohol reacts with another aromatic compound to yield a diarylation product. ${ }^{85}$ A number of diarylated syntheses catalyzed by a superacid has been reported in the literature. The protonation of the 1,2-dicarbonyl group, ${ }^{62,96,97}$ aldehydes, ${ }^{98,99}$ nitriles $^{100}$ and other systems ${ }^{101-105}$ resulted in the formation of highly reactive dication intermediates, which are sufficiently condensed with aromatic compounds. ${ }^{106}$ By applying this concept, Zolotukhin et al. ${ }^{107}$ recently reported that a linear poly(phenylene ether) with a high MW was prepared by polycondensation of 2,2,2trifluoroacetophenone with 4,4'-diphenoxybenzophenone in TFSA at room temperature. On the basis of these findings, a new $\mathrm{AB}_{2}$ monomer with the 2,2,2-trifluoroacetophenone structure was designed and synthesized, aiming at the synthesis of a hyperbranched poly(phenylene ether) with a $100 \% \mathrm{DB}$. Surprisingly, it was found that polymerization of 2,2,2-trifluoro-1-[4-(4-phenoxyphenoxy)pheny1] ethanone as the $\mathrm{AB}_{2}$ monomer in TFSA produced a linear polymer, instead of an HBP (Scheme 21). ${ }^{108}$ From the model reactions between 2,2,2-trifluoroacetophenone and anisole in TFSA, it was found that the first reaction, that is, the formation of an intermediate from a reaction between the 2,2,2-trifluoroacetophenone and phenoxy units, is considerably faster than the second reaction, that is, the reaction of the generated mono-substituted product with one more phenoxy unit.

According to the observation of Olah, ${ }^{106}$ a superacid is a highly ionizing and low-nucleophilicity media. Unexpectedly, the primarily formed electrophile was activated by further superelectrophilic solvation, which is an interaction between the electrophile and Lewis/ Brønsted superacid. Such an interaction of these cations can only exist in a superacid medium, resulting in extremely reactive dication species in the condensed state. Olah et al. ${ }^{98}$ and Shudo and colleagues ${ }^{99}$ suggested that a similar dication intermediate was predominant in the Friedel-Crafts reaction of the carbonyl compound with benzene in a superacid, although Fomine and colleagues ${ }^{109}$ and Zolotukhin and colleagues ${ }^{110}$ proposed a different mechanism by calculation, resulting in only the monocation intermediate without the formation of a dication. On the basis of Olah's proposal, in addition to the results of the model reaction between 2,2,2-trifluoroacetophenone and anisole in TFSA, the mechanism is postulated as shown in Scheme 22(a), in which the diprotonated carbonyl compound in a superacid condenses with anisole to yield an intermediate monocation compound, the reactivity of which is lower than that of the dication.

Self-polycondensation of the $\mathrm{AB}_{2}$ monomer of 1-[4-(4-phenoxyphenoxy)phenyl]ethanone in TFSA is expected to yield a linear polymer the main chain of which can be easily in situ functionalized by further reacting with nucleophiles, because a relatively stable but reactive mono-carbocation still remains at each repeating monomer unit in the generated polymer. In practice, poly(phenylene ether)s 

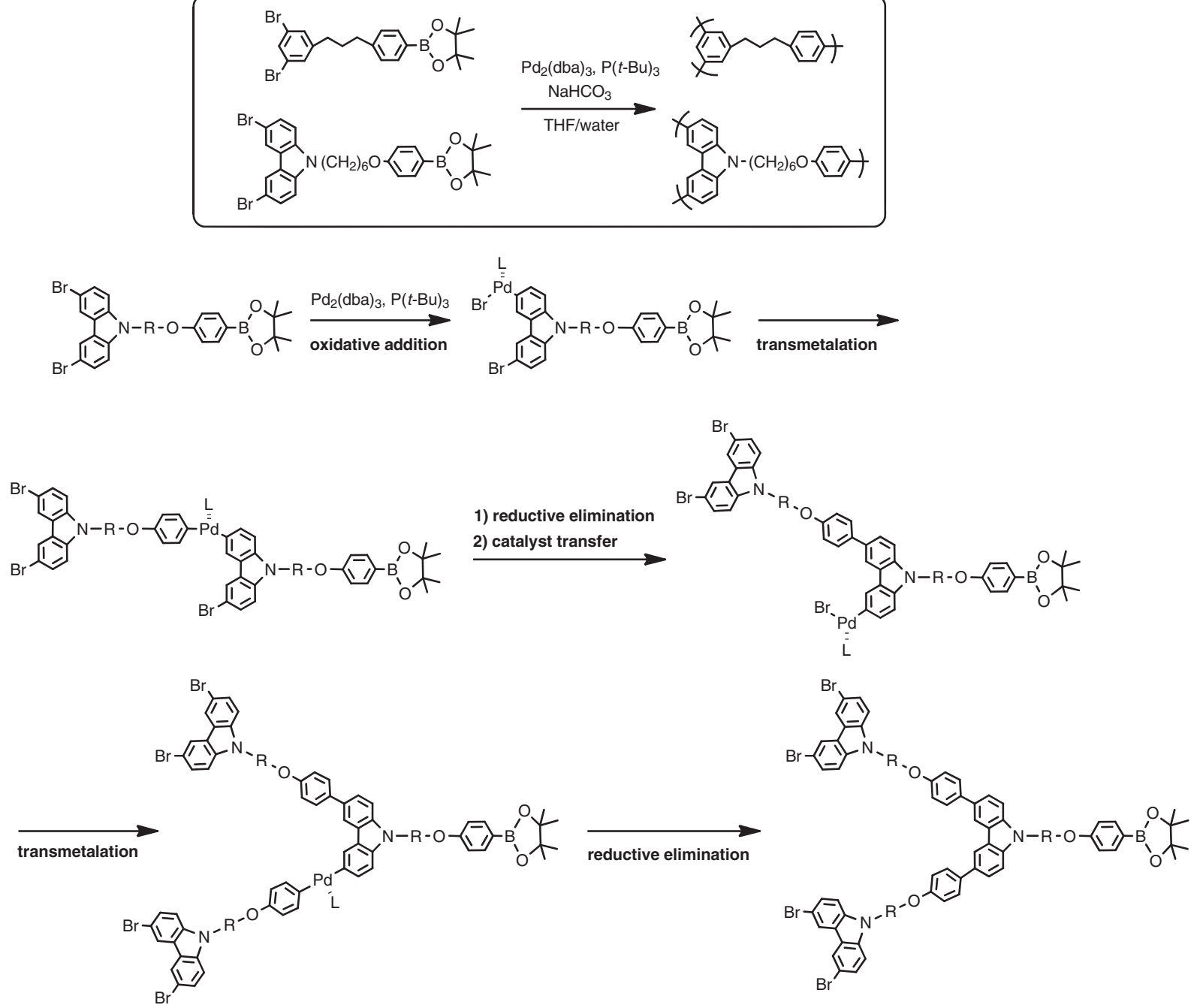

Scheme 20 Synthesis of HBP with 100\% DB by catalyst transfer Suzuki-Miyaura polycondensation. ${ }^{95}$ DB, degree of branching; HBP, hyperbranched polymer.

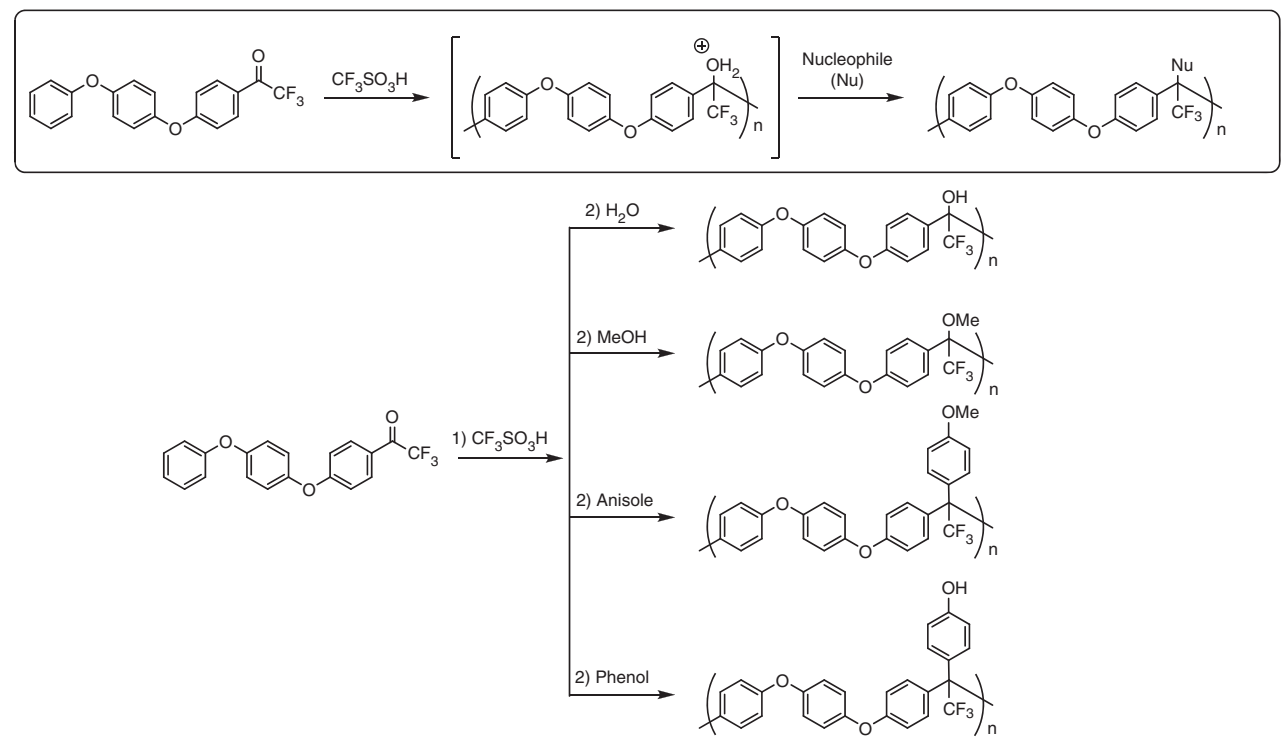

Scheme 21 Synthesis of linear polymer from $\mathrm{AB}_{2}$ monomer. ${ }^{108}$ 
a<smiles>COc1ccc(C(C)(N)c2ccc(C(C)(C)C)cc2)cc1</smiles>
Dication intermediate

b

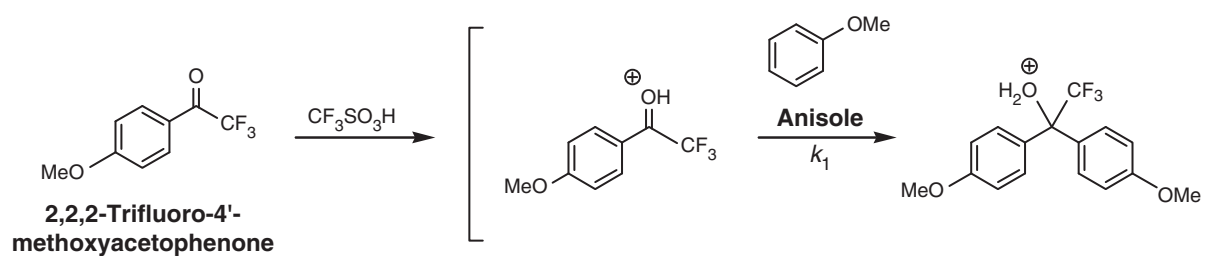
methoxyacetophenone

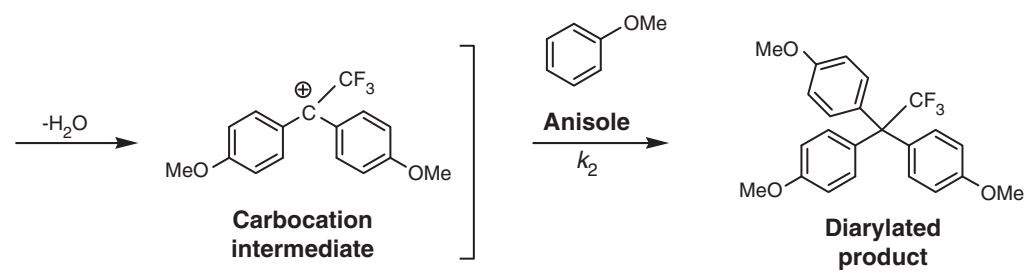

Scheme 22 Plausible reaction mechanism of (a) the reaction of 2,2,2-trifluoroacetophenone and anisole in TFSA and (b) the reaction of 2,2,2-trifluoro-4'methoxyacetophenone with anisole in an equimolar ratio of [TFSA]/[2,2,2-trifluoro-4'-methoxyacetophenone]. ${ }^{108,111}$ TFSA, trifluoromethanesulfonic acid.

with several functional groups at each repeating monomer unit were successfully prepared in nearly quantitative yields, by simply pouring the polymerization solution into various work-up nucleophilic solvents, such as methanol, anisole and phenol (Scheme 21). ${ }^{108}$

\section{HBPS WITH CONTROLLED DB FROM 0 TO $100 \%$}

Quite recently, the first synthesis of HBPs with controlled DBs by one-pot polycondensation of an $\mathrm{AB}_{2}$ monomer of 1-[4-(4-phenoxyphenoxy)phenyl]ethanone was reported in various molar ratios of TFSA to the monomer. ${ }^{111}$ It was newly found that an HBP with a $100 \%$ DB was produced in an equimolar ratio of the [TFSA]/ [monomer] in chloroform, whereas a linear polymer, that is, an HBP with a $0 \%$ DB, was obtained using TFSA as the solvent, as already described in the preceding section. In addition, HBPs with a DB of any percentage between 0 and $100 \%$ are also formed simply by changing the ratio of the $[$ TFSA $] /[$ monomer]. To date, no other examples have been reported for the synthesis of HBPs with a controlled $\mathrm{DB}$ from 0 to $100 \%$ derived from the same $\mathrm{AB}_{2}$ monomer. The model reactions of an equimolar amount of 2,2,2-trifluoro-4'methoxyacetophenone with anisole by changing the ratios of [TFSA] to [2,2,2-trifluoro- $4^{\prime}$-methoxyacetophenone] at room temperature was monitored by ${ }^{1} \mathrm{H}-\mathrm{NMR}$. As a result, only the diarylated product, 2,2,2-trifluoro-1,1,1-tri(4-methoxyphenyl)ethane was selectively obtained in an equimolar ratio of [TFSA]/[2,2,2-trifluoro- $4^{\prime}$-methoxyacetophenone], whereas a monoarylated product, 2,2,2-trifluoro1,1-bis(4-methoxyphenyl)-1-methoxyethane, was quantitatively formed in the molar ratio $>7$. When the molar ratio between 2 and 6 is used, a mixture of the monoarylated and diarylated products is isolated in all cases, in which the ratio of the diarylated product to the monodiarylated product increases by increasing the ratio of [TFSA]/[2,2,2-trifluoro-4'-methoxyacetophenone], which means that the ratios of the rate constants, $\mathrm{k}_{1} / \mathrm{k}_{2}$, for the monoarylation $\left(\mathrm{k}_{1}\right)$ and diarylation steps $\left(\mathrm{k}_{2}\right)$ are between 0 and $100 .^{53}$
These results suggest that condensation of 2,2,2-trifluoro-4'-methoxyacetophenone with anisole in an equimolar ratio of [TFSA]/[2,2,2trifluoro- 4 '-methoxyacetophenone] proceeds through the intermediate carbocation (Scheme 22(b)), the reactivity of which is much higher than that of the starting compound, 2,2,2-trifluoro- $4^{\prime}$-methoxyacetophenone. Therefore, when the intermediate is formed in a mixture, it will be readily attacked by anisole to provide the diarylated product, in which $k_{2}$ is higher than $k_{1}$. On the other hand, for molar ratios of [TFSA]/[2,2,2-trifluoro-4'-methoxyacetophenone] $>7, \mathrm{k}_{2}$ becomes considerably lower than $\mathrm{k}_{1}$.

On the basis of the results of these model reactions, self-polycondensation of an $\mathrm{AB}_{2}$ monomer of 1-[4-(4-phenoxyphenoxy)phenyl] ethanone was carried out in various molar ratios of the [TFSA]/ [monomer] in $\mathrm{CHCl}_{3}$ at room temperature (Scheme 23). An HBP with a $100 \%$ DB was produced using an equimolar ratio of the [TFSA]/ [monomer], whereas a linear polymer $(\mathrm{DB}=0 \%)$ was obtained using TFSA as the solvent. Moreover, HBPs with a DB of any percentage between 0 and $100 \%$ are formed by changing the [TFSA]/[monomer] ratio. The ${ }^{1} \mathrm{H}-\mathrm{NMR}$ spectra of $\mathrm{HBPs}$ with various $\mathrm{DBs}$ are shown in Figure 7. The DB of HBPs was determined by the ratio of the $o$-phenyl proton (HBP2a) at 8.1 p.p.m. for the terminal unit and the methoxy protons (HBP2b) at 3.3 p.p.m. for the linear unit. The DB of HBPs proportionally decreases by increasing the [TFSA]/[monomer] molar ratio, as expected from the results of the model reactions.

In summary, the first synthesis of a linear polymer, HBPs with various $\mathrm{DBs}$, and an $\mathrm{HBP}$ with a $100 \% \mathrm{DB}$ was demonstrated by selfpolycondensation of the same $\mathrm{AB}_{2}$ monomer, 1-[4-(4-phenoxyphenoxy)phenyl] ethanone, in the proper [TFSA]/[monomer] molar ratios. These polymerizations relied on the change in the rate-determination steps for the monoarylation and diarylation of 2,2,2-trifluoroacetophenone by changing the $[\mathrm{TFSA}] /[$ monomer] molar ratios. Such new findings will promote the synthesis of various series of HBPs with controlled DBs and their application to functional materials. 


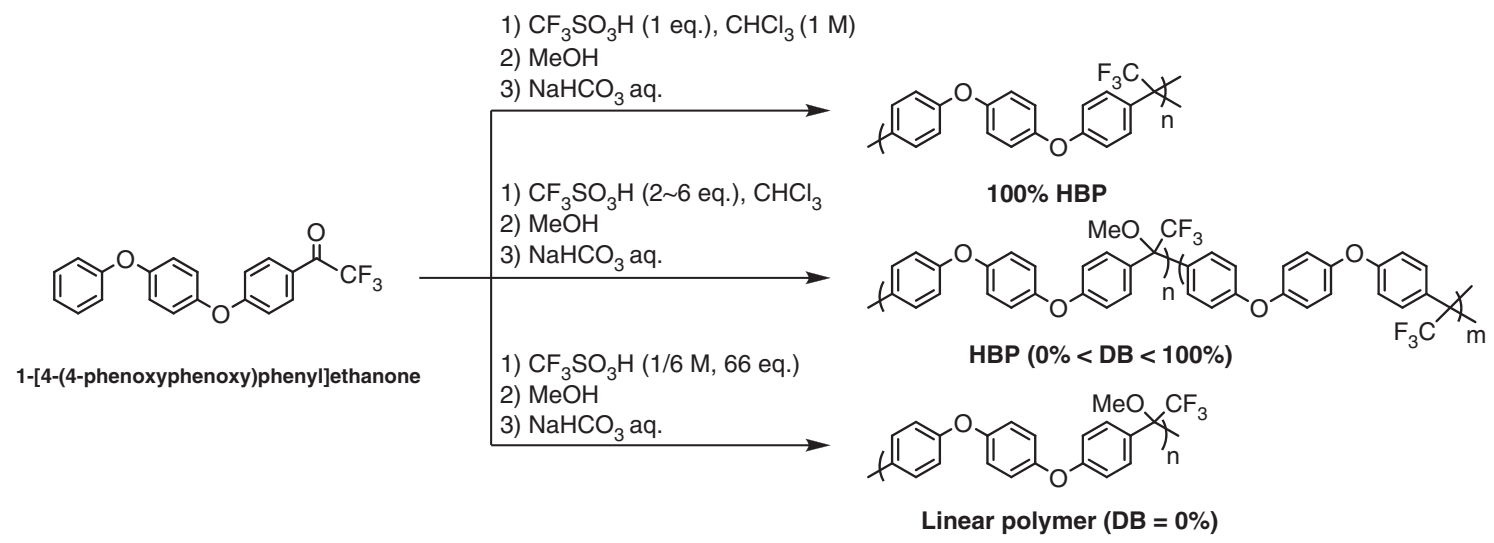

Scheme 23 Synthesis of HBPs with controlled DB from 0 to $100 \%{ }^{111}$ DB, degree of branching; HBP, hyperbranched polymer.
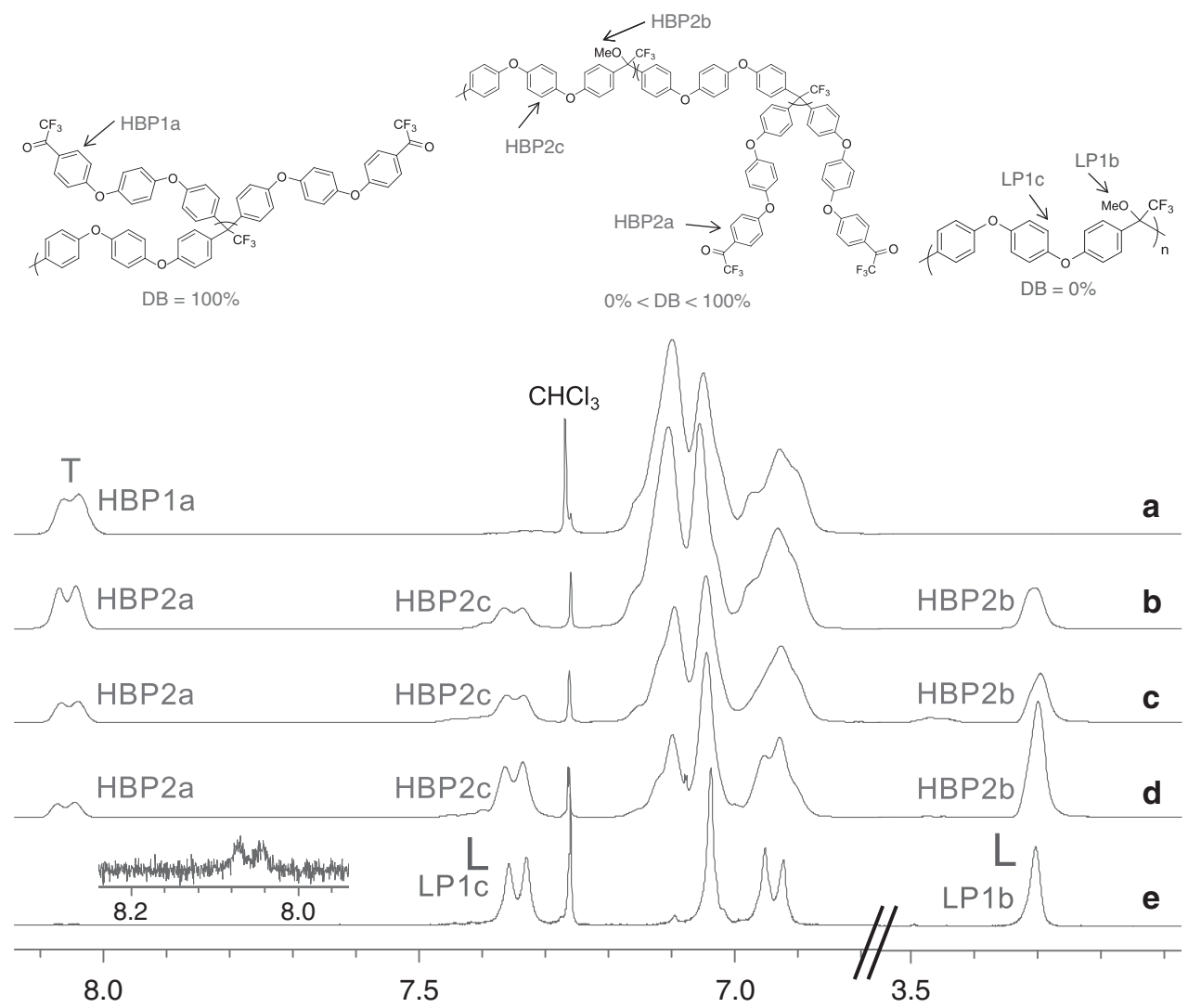

Figure $7{ }^{1} \mathrm{H}-\mathrm{NMR}$ spectra of $\mathrm{HBPs}$ with various $\mathrm{DBs} .{ }^{111}$ (a) $\mathrm{DB}=100 \%$, (b) $\mathrm{DB}=76 \%$, (c) $\mathrm{DB}=52 \%$, (d) $\mathrm{DB}=32 \%$, and (e) $\mathrm{DB}=0 \%$. $\mathrm{DB}$, degree of branching; HBP, hyperbranched polymer; ${ }^{1} \mathrm{H}-\mathrm{NMR},{ }^{1} \mathrm{H}$-nuclear magnetic resonance. A full color version of this figure is available at Polymer Journal online.

\section{CONCLUSIONS}

This paper reviews the synthetic strategies for HBPs with controlled DBs by specially designing monomer architectures and controlling polymerization conditions, although conventional HBPs have randomly branched structures and their DB reaches only $\sim 50 \%$, as summarized in Table 1. Several research groups have overcome the statistical determination of $\mathrm{DB}$ in a random polymerization. The requirements for achieving the synthesis of HBPs with a $100 \%$ $\mathrm{DB}$ or $0 \% \mathrm{DB}$, that is, linear polymers from $\mathrm{AB}_{2}$ monomers are as follows.
(1) The rate constant of the second substitution $\left(\mathrm{k}_{2}\right)$ must be much faster than that of the first one $\left(\mathrm{k}_{1}\right)$ (for $100 \% \mathrm{DB}$ ) or vice versa (for $0 \% \mathrm{DB}$ ).

(2) The second (for $100 \% \mathrm{DB}$ ) or the first (for $0 \%$ ) reaction step must obey the second-order kinetics.

(3) No side reaction occurs during polymerization.

By tuning the rate constants $\mathrm{k}_{1}$ and $\mathrm{k}_{2}$, the preparation of HBPs with any DB percentage has also been demonstrated. 
Table 1 Summary of hyperbranched polymers with controlled degree of branching

\begin{tabular}{|c|c|c|}
\hline Type of polymer and/or method & $D B(\%)$ & References \\
\hline $\begin{array}{l}\text { Poly(ether ketone) using } \mathrm{AB}_{\mathrm{x}}(x>2) \\
\text { monomers }\end{array}$ & 71 & Hawker and $\mathrm{Chu}^{30}$ \\
\hline $\begin{array}{l}\text { Aromatic polyamides using } \\
\mathrm{AB}_{2}+\mathrm{AB}_{4} \text { monomers }\end{array}$ & 72 & Ishida et al. ${ }^{50}$ \\
\hline $\begin{array}{l}\text { Aliphatic polyesters using } \mathrm{AB}_{2}+\mathrm{B}_{3} \\
\text { monomers }\end{array}$ & 80 & $\begin{array}{l}\text { Malmstroem et al. } .^{51} ; \\
\text { Malmstroem and Hult52 }\end{array}$ \\
\hline $\begin{array}{l}\text { Poly(triallylsilane) by chain medica- } \\
\text { tion }\end{array}$ & 100 & Lach and Frey ${ }^{56}$ \\
\hline $\begin{array}{l}\text { Cycloaddition of azine and diiso- } \\
\text { cyanate }\end{array}$ & 100 & Maier et al. ${ }^{57}$ \\
\hline Poly(arylene oxindole) & 100 & Smet et al. ${ }^{58}$ \\
\hline Poly(acenaphthenone) & 100 & Fu et al. ${ }^{61}$ \\
\hline Poly(fluorenone) & 100 & Kono et al. ${ }^{67}$ \\
\hline Poly(thioketal) & 100 & Sinananwanich and $\mathrm{Ueda}^{74}$ \\
\hline Use of pyperidine-2-one compounds & 100 & Sinananwanich et al. ${ }^{86}$ \\
\hline Use of indoline-2-one compounds & 100 & Sinananwanich et al. ${ }^{90}$ \\
\hline $\begin{array}{l}\text { By catalyst transfer Suzuki-Miyaura } \\
\text { polycondensation }\end{array}$ & 100 & Huang et al. .95 \\
\hline Poly(arylene ether) & 0 & Segawa et al. ${ }^{108}$ \\
\hline Poly(arylene ether) & $0-100$ & $\begin{array}{l}\text { Segawa et al. }{ }^{108} ; \\
\text { Segawa et al. }{ }^{111}\end{array}$ \\
\hline
\end{tabular}

Abbreviation: DB, degree of branching.

Dendrimers are attractive scaffolds because of their well-defined and unique macromolecular structures. However, synthesis of dendrimers often requires repetitive protection-deprotection and purification processes for each generation of the dendrimer syntheses. Therefore, it is highly desired to develop new strategies which can eliminate such tedious multistep processes. An HBP with a controlled $\mathrm{DB}$, especially for $100 \% \mathrm{DB}$, is the best candidate for a dendrimer analog because it satisfied some characteristic properties of the dendrimers. However, the current methodologies have not yet achieved a monodispersity or even low polydispersity, which is a key characteristic for dendrimers. Therefore, the next step should be the synthesis of an HBP with a $100 \%$ DB and low polydispersity in a onepot process, which is quite challenging and important from the viewpoint of academia and industry.

\section{CONFLICT OF INTEREST}

The authors declare no conflict of interest.

\section{ACKNOWLEDGEMENTS}

YS thanks the Yoshida Scholarship Foundation for the financial support.

1 Tomalia, D. A., Baker, H., Dewald, J., Hall, M., Kallos, G., Martin, J. R., Ryder, J. \& Smith, P. A new class of polymers: starburst-dendritic macromolecules. Polym. J. 17, 117-132 (1985).

2 Newkome, G. R., Yao, Z., Baker, G. R. \& Gupta, V. K. Micelles. Part 1. Cascade molecules: a new approach to micelles. A [27]-arborol. J. Org. Chem. 50, 2003-2004 (1985).

3 Tomalia, D. A., Baker, H., Dewald, J., Hall, M., Kallos, G., Martin, J. R., Roeck, J., Ryder, J. \& Smith, P. Dendritic macromolecules: synthesis of starburst dendrimers. Macromolecules 19, 2466-2468 (1986).

4 Tomalia, D. A., Hedstrand, D. M. \& Ferritto, M. S. Comb-burst dendrimer topology: new macromolecular architecture derived from dendritic grafting. Macromolecules 24 1435-1438 (1991)
5 de Brabander-van den Berg, E. M. M. \& Meijer, E. W. Poly(propylenimine) dendrimers: large-scale synthesis via heterogeneously catalyzed hydrogenation. Angew. Chem. Int. Ed. Engl. 32, 1308-1311 (1993).

6 de Brabander-van den Berg, E. M. M., Nijenhuis, A., Mure, M., Keulen, J., Reintjens, R., Vandenbooren, F., Bosman, B., de Raat, R., Frijns, T., van den Wal, S., Castelijns, M., Put, J. \& Meijei, E. W. Large-scale production of polypropylenimine dendrimers. Macrmol. Symp. 77, 51-62 (1994).

7 Hawker, C. J. \& Fréchet, J. M. J. Preparation of polymers with controlled molecular architecture. A new convergent approach to dendritic macromolecules. J. Am. Chem. Soc. 112, 7638-7647 (1990).

8 Hawker, C. J. \& Fréchet, J. M. J. A new convergent approach to monodisperse dendritic macromolecules. J. Chem. Soc. Chem. Commun. 1010-1013 (1990).

9 Wooley, K. L., Hawker, C. J. \& Fréchet, J. M. J. Polymers with controlled molecular architecture: control of surface functionality in the synthesis of dendritic hyperbranched macromolecules using the convergent approach. J. Chem. Soc. Perkin Trans. 1, 1059-1079 (1991).

10 Miller, T. M., Kwock, E. W. \& Neenan, T. X. Synthesis of four generations of monodisperse aryl ester dendrimers based on 1,3,5-benzenetricarboxylic acid. Macromolecules 25, 3143-3148 (1992).

11 Hawker, C. J. \& Fréchet, J. M. J. Monodispersed dendritic polyesters with removable chain ends: a versatile approach to globular macromolecules with chemically reversible polarities. J. Chem. Soc. Perkin Trans. 1, 2459-2469 (1992).

12 Buyle Padias, A., Hall, H. K., Tomalia, D. A. \& McConnell, J. R. Starburst polyether dendrimers. J. Org. Chem. 52, 5305-5312 (1987).

13 Ihre, I., Hult, A. \& Soderline, E. Synthesis, characterization, and ${ }^{1} \mathrm{H}$ NMR selfdiffusion studies of dendritic aliphatic polyesters based on 2,2-bis(hydroxymethyl)propionic acid and 1,1,1-tris(hydroxyphenyl)ethane. J. Am. Chem. Soc. 27, 6388-6395 (1996)

14 Newkome, G. R., Moorefield, C. N., Baker, G. R., Johnson, A. L. \& Behera, R. K. Chemistry of micelles. 11. Alkane cascade polymers with a micellar topology: micelle acid derivatives. Angew. Chem. Int. Ed. Engl. 30, 1176-1178 (1991).

15 Newkome, G. R., Moorefield, C. N., Baker, G. R., Saunders, M. J. \& Grossman, S. H. Chemistry of micelles. 13. Monomolecular micelles. Angew. Chem. Int. Ed. Engl. 30, 1178-1180 (1991).

16 Miller, T. M., Neenan, T. X., Zayas, R. \& Bair, H. E. Synthesis and characterization of a series of monodisperse, 1,3,5-phenylene-based hydrocarbon dendrimers including $\mathrm{C} 276 \mathrm{H} 186$ and their fluorinated analogs. J. Am. Chem. Soc. 114, 1018-1025 (1992).

17 Van der Made, A. W. \& van Leeuwen, P.W.N.M. Silane dendrimers. J. Chem. Soc. Chem. Commun. 1400-1401 (1992).

18 Newkome, G. R., Moorefield, C. N. \& Vögtle, F. in Dendrimers and Dendrons, Concepts, Syntheses, Applications (VCH, Weinheim, Germany, 2001).

19 Fréchet, J. M. J. \& Tomalia, D. A. in Dendrimer and Other Dendritic Polymers (VCH, Weinheim, Germany, 2002).

20 Grayson, S. M. \& Fréchet, J. M. J. Convergent dendrons and dendrimers: from synthesis to applications. Chem. Rev. 101, 3819-3868 (2001).

21 Liang, C. \& Fréchet, J. M. J. Applying key concepts from nature: transition state stabilization, pre-concentration and cooperativity effects in dendritic biomimetics. Prog. Polym. Sci. 30, 385-402 (2005).

22 Boas, U., Christensen, J. B. \& Heegaard, P. M. H. Dendrimers: design, synthesis and chemical properties. J. Mater. Chem. 16, 3785-3798 (2006).

23 Lo, S. C. \& Burn, P. L. Development of dendrimers: macromolecules for use in organic light-emitting diodes and solar cells. Chem. Rev. 107, 1097-1116 (2007).

24 Jikei, M. \& Kakimoto, M. Hyperbranched polymers: a promising new class of materials. Prog. Polym. Sci. 26, 1233-1285 (2001).

$25 \mathrm{Kim}$, Y. H. Hyperbranched polymers 10 years after. J. Polym. Sci. Part-A, Polym. Chem. 36, 1685-1698 (1998)

26 Gao, C. \& Yan, D. Hyperbranched polymers: from synthesis to applications. Prog. Polym. Sci. 29, 183-275 (2004)

27 Voit, B. J. Hyperbranched polymers-all problems solved after 15 years of research? J. Polym. Sci. Part-A, Polym. Chem. 43, $2679-2699$ (2005).

28 Hult, A., Johansson, M. \& Malmstrom, E. Hyperbranched polymers. Adv. Polym. Sci. 143, 1-34 (1999).

29 Hawker, C. J. Dendritic and hyperbranched macromolecules-precisely controlled macromolecular architectures. Adv. Polym. Sci. 147, 113-160 (1999).

30 Hawker, C. J. \& Chu, F. Hyperbranched poly(ether ketones): manipulation of structure and physical properties. Macromolecules 29, 4370-4380 (1996)

31 Miravet, J. F. \& Fréchet, J. M. J. New hyperbranched poly(siloxysilanes): variation of the branching pattern and end-functionalization. Macromolecules 31, 3461-3468 (1998).

32 Turner, S. R., Walter, F., Voit, B. I. \& Mourey, T. H. Hyperbranched aromatic polyesters with carboxylic acid terminal groups. Macromolecules 27, 1611-1616 (1994)

33 Uhrich, K. E., Hawker, C. J., Fréchet, J. M. J. \& Turner, S. R. One-pot synthesis of hyperbranched polyethers. Macromolecules 25, 4583-4587 (1992).

34 Fréchet, J. M. J., Henmi, M., Gitsov, I., Aoshima, S., Leduc, M. R. \& Grubbs, R. B. Self-condensing vinyl polymerization: an approach to dendritic materials. Science 269, 1080-1083 (1995).

35 Sunder, A., Hanselmann, R., Frey, H. \& Mulhaupt, R. Controlled synthesis of hyperbranched polyglycerols by ring-opening multibranching polymerization. Macromolecules 32, 4240-4246 (1999).

36 Kim, Y. H. \& Webster, O. W. Hyperbranched polyphenylenes. Macromolecules 25, 5561-5572 (1992) 
37 Mourey, T. H., Turner, S. R., Rubinstein, M., Fréchet, J. M. J., Hawker, C. J. \& Wooley, K. L. Unique behavior of dendritic macromolecules: intrinsic viscosity of polyether dendrimers. Macromolecules 25, 2401-2406 (1992).

38 Turner, S. R., Voit, B. I. \& Mourey, T. H. All-aromatic hyperbranched polyesters with phenol and acetate end groups: synthesis and characterization. Macromolecules 26, 4617-4623 (1993)

39 Percec, V. \& Kawasumi, M. Synthesis and characterization of a thermotropic nematic liquid crystalline dendrimeric polymer. Macromolecules 25, 3843-3850 (1992)

40 Percec, V., Chu, P. \& Kawasumi, M. Toward 'willowlike' thermotropic dendrimers. Macromolecules 27, 4441-4453 (1994).

41 Malmstrom, E., Johansson, M. \& Hult, A. The effect of terminal alkyl chains on hyperbranched polyesters based on 2,2-bis(hydroxymethyl)propionic acid. Macromol. Chem. Phys. 197, 3199-3207 (1996).

42 Kim, Y. H. \& Beckerbauer, R. Role of end groups on the glass transition of hyperbranched polyphenylene and triphenylbenzene derivatives. Macromolecules 27, 1968-1971 (1994).

43 Voit, B. I. Dendritic polymers: from aesthetic macromolecules to commercially interesting materials. Acta Polym. 46, 87-99 (1995).

44 Malmstrom, E., Johansson, M. \& Hult, A. Hyperbranched aliphatic polyesters. Macromolecules 28, 1698-1703 (1995).

45 Salamone, J. C. in The Polymeric Materials Encyclopedia: Synthesis, Properties and Application (CRC Press, Boca Raton, Florida, 1996).

46 Hawker, C. J., Lee, R. \& Fréchet, J. M. J. One-step synthesis of hyperbranched dendritic polyesters. J. Am. Chem. Soc. 113, 4583-4588 (1991).

47 Holter, D., Burgath, A. \& Frey, H. Degree of branching in hyperbranched polymers. Acta Polym. 48, 30-35 (1997)

48 Hobson, L. J. \& Feast, W. J. A simple 'one pot' route to the hyperbranched analogs of Tomalia's poly(amidoamine) dendrimers. Chem. Commun. 1877-1878 (1997).

49 Kambouris, P. \& Hawker, C. J. A versatile new method for structure determination in hyperbranched macromolecules. J. Chem. Soc. Perkin Trans. 1 2717-2721 (1993).

50 Ishida, Y., Sun, A. C. F., Jikei, M. \& Kakimoto, M. Synthesis of hyperbranched aromatic polyamides starting from dendrons as $A_{x}$ monomers: effect of monomer multiplicity on the degree of branching. Macromolecules 33, 2832-2838 (2000).

51 Malmstroem, E., Johansson, M. \& Hult, A. Hyperbranched aliphatic polyesters. Macromolecules 28, 1698-1703 (1995).

52 Malmstroem, E. \& Hult, A. Kinetics of formation of hyperbranched polyesters based on 2,2-bis(methylol)propionic acid. Macromolecules 29, 1222-1228 (1996).

53 Holter, D. \& Frey, H. Degree of branching (DB) in hyperbranched polymers. Part 2. Enhancement of the DB. Scope and limitations. Acta Polym. 48, 298-309 (1997).

54 Suzuki, M., li, A. \& Saegusa, T. Multibranching polymerization: palladium-catalyzed ring-opening polymerization of cyclic carbamate to produce hyperbranched dendritic polyamine. Macromolecules 25, 7071-7072 (1992).

55 Suzuki, M., Yoshida, S., Shiraga, K. \& Saegusa, T. New ring-opening polymerization via a $\pi$-allylpalladium complex. 5 . Multibranching polymerization of cyclic carbamate to produce hyperbranched dendritic polyamine. Macromolecules 31, 1716-1719 (1998).

56 Lach, C. \& Frey, H. Enhancing the degree of branching of hyperbranched polymers by postsynthetic modification. Macromolecules 31, 2381-2383 (1998).

57 Maier, G., Zech, C., Voit, B. \& Komber, H. An approach to hyperbranched polymers with a degree of branching of 100\%. Macromol. Chem. Phys. 199, 2655-2664 (1998)

58 Smet, M., Schacht, E. H. \& Dehaen, W. Synthesis, characterization, and modification of hyperbranched poly(arylene oxindoles) with a degree of branching of $100 \%$. Angew. Chem. Int. Ed. 41, 4547-4550 (2002).

59 Fu, Y., Van Oosterwijck, C., Vandendriessche, A., Kowalczuk-Bleja, A., Zhang, X., Dworak, A., Dehaen, W. \& Smet, M. Hyperbranched poly(arylene oxindole)s with a degree of branching of $100 \%$ for the construction of nanocontainers by orthogonal modification. Macromolecules 41, 2388-2393 (2008).

60 Kowalczuk, A., Vandendriessche, A., Trzebicka, B., Mendrek, B., Szeluga, U., Cholewinski, G., Smet, M., Dworak, A. \& Dehaen, W. Core-shell nanoparticles with hyperbranched poly(arylene-oxindole) interiors. J. Polym. Sci., Part A: Polym. Chem. 47, 1120-1135 (2009).

61 Fu, Y., Vandendriessche, A., Dehaen, W. \& Smet, M. Effective acid-catalyzed synthesis of $100 \%$ hyperbranched polyacenaphthenones. Macromolecules 39, 5183-5186 (2006).

62 Yamazaki, T., Saito, S., Ohwada, T. \& Shudo, K. Acid-catalyzed reactions of 1,2dicarbonylethanes with benzene. Ethylene dication electrophiles. Tetrahedron Lett. 36, 5749-5752 (1995).

63 Suzuki, T., Ohwada, T. \& Shudo, K. Superacid-catalyzed electrocyclization of 1phenyl-2-propen-1-ones to 1-indanones. Kinetic and theoretical studies of electrocyclization of oxonium-carbenium dications. J. Am. Chem. Soc. 119, 6774-6780 (1997).

64 Klumpp, D. A. \& Lau, S. 3-Pyridinecarboxaldehyde: a model system for superelectrophilic activation and the observation of a diprotonated electrophile. J. Org. Chem. 64, 7309-7311 (1999).

65 Morgan, P. W. Aromatic polyesters with large cross-planar substituents. Macromolecules 3, 536-544 (1970).

66 Yamada, M., Sun, J., Suda, Y. \& Nakaya, T. Synthesis of fluorenebisphenoxy derivatives by acid-sulfur compound catalyzed condensation reaction. Chem. Lett. 27, 1055-1056 (1998)

67 Kono, S., Sinananwanich, W., Shibasaki, Y., Ando, S. \& Ueda, M. Synthesis of hyperbranched polymer with degree of branching of approximately $100 \%$ by polycondensation of 2-(4-phenoxyphenoxy)fluorenone. Polym. J. 39, 1150-1156 (2007).
68 Loewenthal, H. J. E. \& McOmie, J. F. W. in Protective Groups in Organic Chemistry 323-402 (Plenum Press, New York, 1973).

69 Greene, T. W. in Protective Groups in Organic Synthesis 349 (John Wiley, New York, 1981).

70 Kumar, V. \& Dev, S. Titanium tetrachloride, an efficient and convenient reagent for thioacetalization. Tetrahedron Lett. 24, 1289-1292 (1983).

71 Corey, E. J. \& Shimoji, K. Magnesium and zinc-catalyzed thioketalization. Tetrahedron Lett. 24, 169-172 (1983)

72 Garlaschelli, L. \& Vidari, G. Anhydrous lanthanum trichloride, a mild and convenient reagent for thioacetalization. Tetrahedron Lett. 31, 5815-5816 (1990).

73 Olah, G. A., Narang, S. C., Meider, D. \& Salem, G. F. Catalysis by solid superacids; 8. Improved Nafion-H perfluorinated resinsulfonic acid-catalyzed preparation of dimethyl acetals and ethylenedithioacetals, and hydrolysis of dimethyl acetals. Synthesis 282-283 (1981)

74 Sinananwanich, W. \& Ueda, M. Synthesis of a hyperbranched polythioketal with $100 \%$ degree of branching. J. Polym. Sci., Part A: Polym. Chem. 46, 2689-2700 (2008).

75 Winstein, S., Shatavsky, M., Norton, C. \& Woodward, R. B. 7-Norbornenyl and 7norbornyl cations. J. Am. Chem. Soc. 77, 4183-4184 (1955).

76 Winstein, S. \& Shatavsky, M. Neighboring carbon and hydrogen. XXI. Anti-7 derivatives of norbornene (bicyclo[2.2.1]heptene) as homoallylic systems. J. Am. Chem. Soc. 78, 592-597 (1956).

77 Bowden, K. \& Grubbs, E. J. Through-bond and through-space models for interpreting chemical reactivity in organic reactions. Chem. Soc. Rev. 25, 171-177 (1996).

78 Roberts, J. D. \& Moreland, W. T. Electrical effects of substituent groups in saturated systems. Reactivities of 4-substituted bicyclo[2.2.2]octane-1-carboxylic acids. J. Am. Chem. Soc. 75, 2167-2173 (1953).

79 Holtz, H. D. \& Stock, L. M. Chemistry of the bicyclo[2.2.2]octanes. III. Dissociation constants for 4-substituted bicyclo[2.2.2]octane-1-carboxylic acids. Empirical and theoretical analysis. J. Am. Chem. Soc. 86, 5188-5194 (1964).

80 Conroy, J. L., Sanders, T. C. \& Seto, C. T. Using the electrostatic field effect to design a new class of inhibitors for cysteine proteases. J. Am. Chem. Soc. 119, 4285-4291 (1997).

81 Klumpp, D. A., Garza, M., Jones, A. \& Mendoza, S. Synthesis of aryl-substituted piperidines by superacid activation of piperidones. J. Org. Chem. 64, 6702-6705 (1999)

82 Geneste, P., Durand, R., Hugon, I. \& Reminiac, C. Influence of the heteroatom in the addition of tetrahydroborate(1-) to the carbonyl group in amino and thio 4-ketones. J. Org. Chem. 44, 1971-1973 (1979).

83 Burkey, T. J. \& Fahey, R. C. Equilibrium studies of water and 3-mercaptopropanoic acid addition to cyclic ketones. J. Org. Chem. 50, 1304-1306 (1985).

84 Das, G. \& Thornton, E. R. Aldol additions of pinacolone lithium enolate with ketones: reactivities governed predominantly by field effects. J. Am. Chem. Soc. 115, 1302-1312 (1993)

85 March, J. in Advance Organic Chemistry, Reactions, Mechanisms, and Structure 548, 4th ed. (Wiley-Interscience Publication, New York, 1992).

86 Sinananwanich, W., Higashihara, T. \& Ueda, M. Synthesis of a hyperbranched polymer with perfect branching based on piperidine-4-one. Macromolecules 42, 994-1001 (2009)

87 Kihara, N., Komatsu, S., Takata, T. \& Endo, T. Significance of stoichiometric imbalance in step polymerization via reactive intermediate. Macromolecules 32, 4776-4783 (1999).

88 Miyatake, K., Hlil, A. R. \& Hay, A. S. High molecular weight aromatic polyformals free of macrocyclic oligomers. A condensative chain polymerization reaction. Macromolecules 34, 4288-4290 (2001).

89 limori, H., Shibasaki, Y., Ando, S. \& Ueda, M. Nonstoichiometric polycondensation I. Synthesis of polythioether from dibromomethane and 4,4'-thiobisbenzenethiol. Macromol. Symp. 199, 23-35 (2003).

90 Sinananwanich, W., Segawa, Y., Higashihara, T. \& Ueda, M. Base-catalyzed synthesis of a $100 \%$ hyperbranched polymer on the basis of an indolin-2-one unit. Macromolecules 42, 8718-8724 (2009).

91 Sinclair, D. J. \& Sherburn, M. S. Single and double Suzuki-Miyaura couplings with symmetric dihalobenzenes. J. Org. Chem. 70, 3730-3733 (2005).

92 Dong, C. G. \& Hu, Q. S. Preferential oxidative addition in palladium(0)-catalyzed Suzuki cross-coupling reactions of dihaloarenes with arylboronic acids. J. Am. Chem. Soc. 127, 10006-10007 (2005)

93 Weber, S. K., Galbrecht, F. \& Scherf, U. Preferential oxidative addition in Suzuki crosscoupling reactions across one fluorene unit. Org. Lett. 8, 4039-4041 (2006).

94 Yokoyama, A., Suzuki, H., Kubota, Y., Ohuchi, K., Higashimura, H. \& Yokozawa, T. Chain-growth polymerization for the synthesis of polyfluorene via Suzuki-Miyaura coupling reaction from an externally added initiator unit. J. Am. Chem. Soc. 129, 7236-7237 (2007).

95 Huang, W., Su, L. \& Bo, Z. Hyperbranched polymers with a degree of branching of $100 \%$ prepared by catalyst transfer Suzuki-Miyaura polycondensation. J. Am. Chem. Soc. 131, 10348-10349 (2009).

96 Klumpp, D. A., Yeung, K. Y., Prakash, G. K. S. \& Olah, G. A. Superacid-activated condensation of parabanic acid and derivatives with arenes. A new synthesis of phenytoin and 5,5-diarylhydantoins. Synlett. 918-920 (1998).

97 Klumpp, A., Yeung, K. Y., Prakash, G. K. S. \& Olah, G. A. Preparation of 3,3 diaryloxindoles by superacid-induced condensations of isatins and aromatics with a combinatorial approach. J. Org. Chem. 63, 4481-4484 (1998).

98 Olah, G. A., Rasul, G., York, C. \& Prakash, G. K. S. Superacid-catalyzed condensation of benzaldehyde with benzene. Study of protonated benzaldehydes and the role of superelectrophilic activation. J. Am. Chem. Soc. 117, 11211-11214 (1995). 
99 Saito, S., Ohwada, T. \& Shudo, K. Friedel-Crafts-type reaction of benzaldehyde with benzene. Diprotonated benzaldehyde as the reactive intermediate. J. Am. Chem. Soc. 117, 11081-11084 (1995).

100 Sato, Y., Yato, M., Ohwada, T., Saito, S. \& Shudo, K. Involvement of dicationic species as the reactive intermediates in Gattermann, Houben-Hoesch, and FriedelCrafts reactions of nonactivated benzenes. J. Am. Chem. Soc. 117, 3037-3043 (1995).

101 Olah, G. A., Klumpp, D. A., Neyer, G. \& Wang, Q. The preparation of substituted phenanthrenes from aryl pinacols in superacid. Synthesis 3, 321-323 (1996).

102 Klumpp, D. A., Baek, D. N., Prakash, G. K. S. \& Olah, G. A. Chemistry in superacids. 23. Preparation of condensed aromatics by superacidic dehydrative cyclization of aryl pinacols and epoxides. J. Org. Chem. 62, 6666-6671 (1997).

103 Olah, G. A., Wang, Q. \& Neyer, G. Superelectrophilic methylthiomethylation of aromatics with chloromethyl methyl sulfide/aluminum chloride $\left(\mathrm{MeSCH}_{2} \mathrm{Cl}: 2 \mathrm{AlCl}_{3}\right)$ reagent. Synthesis 3, 276-278 (1994).

104 Saito, S., Sato, Y., Ohwada, T. \& Shudo, K. Friedel-Crafts-type cyclodehydration of 1,3-diphenyl-1-propanones. Kinetic evidence for the involvement of dication. J. Am. Chem. Soc. 116, 2312-2317 (1994).
105 Yokoyama, A., Ohwada, T. \& Shudo, K. Prototype pictet-spengler reactions catalyzed by superacids. Involvement of dicationic superelectrophiles. J. Org. Chem. 64, 611-617 (1999).

106 Olah, G. A. Superelectrophiles. Angew. Chem. Int. Ed. Engl. 32, 767-788 (1993)

107 Zolotukhin, M., Fomine, S., Salcedo, R. \& Khalilov, C. Remarkable enhancement of reactivity of carbonyl compounds for polymerizations with non-activated aromatic hydrocarbons. Chem. Commun. 1030-1031 (2004).

108 Segawa, Y., Sinananwanich, W. \& Ueda, M. Facile synthesis of poly(phenylene ether) and 'in-situ' functionalization of polymer backbones. Macromolecules 41, 8309-8311 (2008)

109 Lopez Lira, A., Zolotukhin, M., Fomina, L. \& Fomine, S. Triflic-acid-mediated polycondensation of carbonyl compounds with aromatic hydrocarbons -a theoretical study. Macromol. Theory Simul. 16, 227-239 (2007).

110 Guzman-Gutierrez, M. T., Nieto, D., Fomine, S., Morales, S. L., Zolotukhin, M. G., Hernandez, M. C. G., Kricheldorf, H. \& Wilks, E. S. Dramatic enhancement of superacid-catalyzed polyhydroxyalkylation reactions. Macromolecules 44, 194-202 (2011).

111 Segawa, Y., Higashihara, T. \& Ueda, M. Hyperbranched polymers with controlled degree of branching from 0 to $100 \%$. J. Am. Chem. Soc. 132, 11000-11001 (2010). 